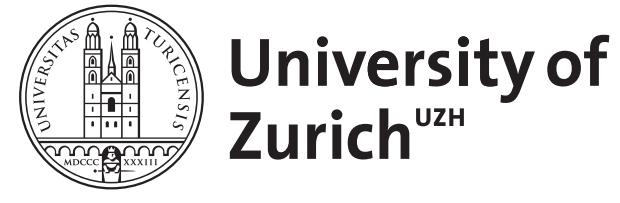

Zurich Open Repository and Archive

University of Zurich

University Library

Strickhofstrasse 39

CH-8057 Zurich

www.zora.uzh.ch

Year: 2011

The strength of strong ties in the creation of innovation

Rost, Katja

DOI: https://doi.org/10.1016/j.respol.2010.12.001

Posted at the Zurich Open Repository and Archive, University of Zurich

ZORA URL: https://doi.org/10.5167/uzh-68483

Journal Article

Accepted Version

Originally published at:

Rost, Katja (2011). The strength of strong ties in the creation of innovation. Research policy, 40(4):588604.

DOI: https://doi.org/10.1016/j.respol.2010.12.001 


\title{
The strength of strong ties in the creation of innovation
}

\author{
Katja Rost ${ }^{\mathrm{a}}$
}

${ }^{\text {a }}$ University of Mannheim, Institute of Economic Sociology, Parkring 47, 68159 Mannheim, Germany, E-mail adresse: karost@ staff.mail.uni-mannheim.de

\begin{abstract}
There is an ongoing debate in innovation research as to which type of social capital is more conducive to innovation: structural holes as proposed by Burt or network closure as proposed by Coleman. Although Coleman focused on the quality of relationships, Burt argued that the structural configuration of relationships was more important. I argue that, instead of being alternative substitutes, Burt's social capital theory complements Coleman's theory. More precisely, I demonstrate that, in the presence of strong ties, weak network architectures (structural holes or a peripheral network position) leverage the strength of strong ties in the creation of innovation. This implies that weak network architectures have no value without strong ties, whereas strong ties have some value without weak network architectures but are leveraged by this type of structure. The findings indicate that innovation research tends to overestimate the impact of weak network architectures in the creation of innovation. By pointing to the necessity of strong ties, the results may be of particular interest for research on open innovation. They suggest that open innovation will not work if closed innovation principles are pushed back.
\end{abstract}

\section{Keywords}

social networks, innovation, James S. Coleman, Ronald S. Burt, strong ties, structural holes, patents 


\section{Introduction}

Research in the area of innovation management proposes that professional networks, that is, a person's direct exchange partners and knowledge or other resources acquired through those partners (Lin, 2001), are central to the knowledge creation process (Amabile, 1996; Inkpen \& Tsang, 2005; McFadyen et al., 2009; Perry-Smith \& Shalley, 2003; Subramaniam \& Youndt, 2005). Sociological theory offers two different views on how professional networks enhance knowledge generation. Although Coleman's view $(1988,1990)$ highlights the solidarity benefits of professional networks, Burt's view $(1992,1997$ a) focuses on information and control benefits. According to Coleman, the closure of professional networks makes actors more willing to share tacit knowledge (Adler \& Kwon, 2002). According to Burt, sparse networks with many structural holes provide access to a wide range of nonredundant information sources (Adler \& Kwon, 2002).

Both theoretical views motivated a large amount of empirical research; most of which assumed a tradeoff between both views and suggested that the validity of one of the views depended on task characteristics (Adler \& Kwon, 2002). For example, Hansen (1999) showed that relatively complex, uncertain tasks benefited from closure, whereas less complex, certain tasks benefited from sparse networks. Uzzi (1997) made a similar point. However, Gabbay and Zuckerman's (1998) study found the opposite to be true: In basic research, which is typically characterized by complex, uncertain tasks, scientists benefit from sparse networks with many holes, whereas in applied research, which is typically characterized by noncomplex, certain tasks, scientists benefit from dense networks. Such ambiguous results have led other studies to propose that successful networks balance the benefits and risks of social capital (Adler \& Kwon, 2002). For example, Perry-Smith and Shalley (2003) argued that networks equilibrating solidarity, information, and control benefits offered the best opportunities to be creative at work. Empirical research supports this assumption by showing that most network measurements (network size, contact frequency, or network centrality) are inverted u-shaped related with knowledge creation (Hargadon \& Sutton, 1997; Leenders et al., 2007; McFadyen \& Cannella, 2004; Rost, 2006; Uzzi \& Spiro, 2005).

In addition, there exists a rarely tested third explanation: Instead of being substitutes, Coleman and Burt may complement each other; that is, the assumption of a trade-off between both views is wrong. For example, McFadyen et al. (2009) showed that scientists who combined strong ties (measured by repeated publications with the same coauthors) with sparse networks (measured by the amount of realized publications with all possible coauthors) published most often in high impact journals. The results tend to support Coleman by 
highlighting the solidarity benefits of strong ties and Burt by highlighting the information and control benefits of sparse networks. A similar point has been made in small-world research that integrates research on tie strength and structural holes (Lin et al., 1978; Milgram, 1967). Small-world research is characterized by a network structure that has both a high level of closure in addition to tie strength in the local cluster and a large number of weak bridging ties with other clusters. Within this research, it is suggested that teams or regions that incorporate the two conditions simultaneously (i.e., strong ties within the cluster and bridging ties with other clusters) are the most creative (Capaldo, 2007; Fleming et al., 2007; Uzzi \& Spiro, 2005). "The implication advanced by small world research for future innovation studies is that both ties strength and structural holes need to be simultaneously examined. Rather than being perceived as two extremes of the same construct, they constitute two constructs residing within different network boundaries..." (Zheng, 2010: 168).

This article considers recent research that states: "few (works) examined both the architecture of the network and the quality and content of the relationships ... Given the additive contribution of the structural and relational dimensions to innovation, it seems promising to explore both dimensions in future studies of innovation..." (Zheng, 2010: 177). In the theoretical part, it is presented in detail that Coleman's view pays attention to the quality of relationships (tie strength), whereas Burt's view pays attention to the structural configuration of relationships (structural holes). As both authors analyzed different features of professional networks, their social capital theories do not contradict each other as often assumed in the former literature.

For actors, it is possible to unite the solidarity benefits of strong ties with the information and control benefits of sparse networks. The hypothesis is that individuals who combine strong relationships with weak network architectures (e.g., structural holes or a peripheral network position) come up with the most innovative solutions. Former research on this topic is refined by pointing out that strong ties, not weak network architectures, are the essential element for innovation: It is proposed that weak network architectures have no value without strong ties, whereas strong ties without weak network architectures have at least some value. It follows that Burt's social capital theory on innovation complements Coleman's social capital theory on innovation; however, the reverse does not work. It is further argued that networks consisting of strongly interconnected elements (dense focal groups consisting of strong ties among actors) are not counterproductive for innovation. Network closure is created within groups and not as structural holes or a peripheral position beyond groups. By 
neglecting the opportunities of a wider social structure, the concept of network closure erroneously assumes that individuals behave "atomized" as blindly obedient to group norms.

To test the hypotheses, I analyzed key inventors of the German automotive industry. I collected egocentric survey data to measure the strength of professional relationships, coinventor data to measure structural features of professional networks, and time-lagged patent citation data to measure knowledge creation. The empirical design is in line with recent suggestions to elaborate network research (Zheng, 2010). It combines objective and subjective measurements to reduce common method biases and to improve construct validity, and it tests the causal link between social capital and innovation. The methodological improvements help to overcome some former research problems that mostly relied on affiliation networks (Capaldo, 2007; Fleming et al., 2007; McFadyen et al., 2009; Uzzi \& Spiro, 2005). Although affiliation networks (coauthors, coinventors, or coprojects) capture the architecture of networks, they insufficiently measure the specific quality and content of relationships. They also do not allow for the control of human capital that is assumed to influence strongly social capital and innovation (Coleman, 1988).

\section{Social capital and innovation}

\subsection{Coleman's view on social capital: relational embeddedness}

Within the literature, Coleman's view $(1988,1990)$ on social networks and correspondingly on social capital is classified as an internal or bonding view (Adler \& Kwon, 2002). This classification is substantiated by Coleman's focus on the emergence of effective norms that promote trustworthiness within an organization or community and thus strengthen social capital. It has led to the assumption that for Coleman the closure of the networks is an important prerequisite for social capital because "in a more open structure, violations of norms are more likely to go undetected and unpunished. People, thus, will be less trusting of one another, weakening social capital..." (Adler \& Kwon, 2002: 24; see also Burt, 2001). Although it is true that Coleman stresses the importance of trustworthiness and effective norms in relationships, Coleman's conclusion emphasizing the closure of networks is sometimes misunderstood.

Coleman points out that the relationship quality between exchange partners is important to explain when social capital investments will capitalize. Underlying this concept is his theory of rational action in which each actor has control over certain resources and interests in certain resources and events (Coleman, 1990). Within this theory, social capital (relationships to other actors) constitutes a particular kind of resource available to an actor (Coleman, 1988, 1990). For Coleman (1988), the value of social capital lies in "outstanding credit slips" on 
both sides of a relationship explaining why "people are always doing things for each other... If $\mathrm{A}$ does something for $\mathrm{B}$ and trusts $\mathrm{B}$ to reciprocate in the future, this establishes an expectation in A and an obligation on the part of B. This obligation can be conceived as a credit slip held by A for performance by B. If A holds a large number of these credit slips, for a number of persons with whom A has relations, then the analogy to financial capital is direct..." (Section 102)

In Coleman's approach, the specific quality of relationships therefore plays a major role. For example, if A's exchange partners are not trustworthy, then debts will not be repaid. Further, in repeated exchanges, the payment of debts often occurs because the shadow of the future confronts exchange partners. Coleman therefore assumes that social capital investments are most valuable if individuals have strong ties with their exchange partners. Tie strength refers to the nature of a relationship that is a combination of the amount of time, emotional intensity, intimacy, and reciprocal services associated with the tie (Granovetter, 1973). The solidarity benefits of strong ties (intensive interactions characterized by mutual trust) become reflected in innovation: As credit slips will be paid back, they allow for the exchange of more complex and proprietary information (Hansen, 1999; Tsai \& Ghoshal, 1998).

Former empirical research tends to support this assumption by showing that frequent communication enhances innovation (Moran, 2005; Reagans \& Zuckerman, 2001; Smith et al., 2005) and, in particular, the radicalness of innovation (Landry et al., 2002). Sociological research further points to the strength of strong ties for assistance and help. For example, Wellman (1979) studied helping networks in a Toronto suburb and showed that 56 percent of the first closest-ranked intimates were relied upon in emergencies, whereas only 16 percent of the sixth closest-ranked intimates were relied upon. A similar point was made by Nelson (1989) who showed that strong ties prevented conflicts within organizations.

The strength of an actor's relationship with contacts, however, is conceptually distinct from network closure or correspondingly a lack of structural holes (Capaldo, 2007; Granovetter, 1973; Reagans \& McEvily, 2003; Zheng, 2010). First, Coleman never claimed that the emergence of effective norms always required network closure. Some types of social norms constituting a form of social capital are effective in the absence of relationships or in dispersed groups (Coleman, 1990). For example, the norm of generalized reciprocity explains why social capital investments are repaid by unknown strangers (Sahlins, 1972). This has been validated by recent experimental work showing that in one-shot situations people make use of sanctioning behavior (Fehr \& Gächter, 2002). Also rules of politeness, as demonstrated in Coleman (1990), are effectively achieved not only in small towns but also in big cities. 
Coleman (1990) also points out the negative externalities of strong social norms in cohesive groups, for example, of elite norms that not only exclude nonmembers but also exercise strong behavioral pressure on group members. Second and often neglected, Coleman's social capital theory remains silent on the information and control benefits of social capital, which often occur due to structural embeddedness. Although information exchanges (everyday interactions to remain up-to-date) constitute a form of social capital, "the relations in this case are not valuable for the 'credit slips' they provide in the form of obligations that one holds for others' performances or for the trustworthiness of the other party but merely for the information they provide..." (Coleman, 1988: Section 104). It is therefore wrong to conclude that Coleman assumes that valuable social capital requires close, cohesive networks or a lack of structural holes. His theory remains rather salient on social capital opportunities emerging due to network structure, but he does extensively discuss why social capital investments are most valuable if relationships between exchange partners are rather strong.

\subsection{Burt's view on social capital: structural embeddedness}

The network literature classifies Burt's view (1992, 1997a) on social networks and correspondingly on social capital as an external or bridging view (Adler \& Kwon, 2002). Burt primarily focused on external ties for competitive goals. He argued that a sparse network with few redundant ties provided great social capital benefits as individuals have the opportunity to broker the flow of information between groups and to act as entrepreneurs.

Burt focused on the information and control consequences of social capital, which Coleman in large part excluded from his analysis. "An individual's position in the structure of ... exchanges can be an asset in its own right ... [Social capital] predicts that returns to intelligence, education, and seniority depend in some part on a person's location in the social structure of a market or hierarchy..." (Burt, 1997a: 339). Building on the strength of weak ties (Granovetter, 1973), the concept of network centrality (Freeman, 1977), and the power of having exclusive exchange partners (Cook, 1977), Burt developed the idea of structural holes; that is, of being the broker in relations between people who were otherwise disconnected in the social structure.

In Burt's approach, the structural configuration of networks plays a major role. First, he hypothesized that networks rich in structural holes offered opportunities to broker the flow of information. That is, as receivers of less redundant information, people are better informed of opportunities or impending disasters, see new opportunities created by needs in one group that could be served by skills in other groups, and have more options of bringing together diverse individuals when it is rewarding. Second, he predicted that networks rich in structural holes 
allowed entrepreneurial behavior by controlling the form of projects that bring together people from opposite sides of the hole: A person who adds value by brokering the connection between two others is the third person to benefit. Information and control benefits become reflected in innovation: Persons with contact networks rich in structural holes move information faster, know the parameters of emerging problems earlier, and tailor solutions to a specific group of individuals.

Former empirical research tends to support this assumption by showing that structural holes enhance innovation (Fleming et al., 2007; Hargadon \& Sutton, 1997; Reagans \& Zuckerman, 2001; Uzzi \& Spiro, 2005). Sociological studies further point to the strength of structural holes (or of bridging weak ties) for the diffusion of information. For example, Granovetter (1974) found in his empirical study of recent job changers that professional, technical, and managerial workers were more likely to hear about new jobs through weak ties (27.8 percent) than through strong ones (16.7 percent). Further, Lin et al.'s (1978) study that consisted of forwarding a booklet to designated but previously unknown target persons through a chain of personal acquaintances showed that successfully completed chains made much more use of weak ties.

A similar idea has been developed in research concerned with a person's position within a network (Freeman, 1977). The hypothesis is that individuals who occupy a peripheral network position enjoy the highest levels of creativity because they are more able to recognize new, divergent ideas and to take advantage of these ideas (Chubin, 1976; Fine \& Kleinman, 1979; Perry-Smith \& Shalley, 2003). Empirical research shows that individuals who combine a low closeness centrality in networks with a low amount of outside ties have the highest creativity (Perry-Smith, 2006). ${ }^{1}$ The negative effects of external ties contradict the assumption that new ideas mainly come from outside (Perry-Smith \& Shalley, 2003), but it may be explained by the high maintenance costs of external ties (Perry-Smith, 2006) or by their low value with respect to tacit knowledge transfer (Hansen, 1999).

\subsection{Structural embeddedness as a complement for relational embeddedness}

The difference between Coleman and Burt reflects the difference between a relational versus structural interpretation of social capital (Granovetter, 1985). Coleman points out solidarity benefits arising from strong relationships. Burt points out information and control benefits arising from sparse networks. As the analysis of networks requires attention to the

\footnotetext{
${ }^{1}$ In a graph representing a social network, closeness centrality measures how close an actor is to all other actors in the graph.
} 
quality of the constituent ties and to their configuration (Adler \& Kwon, 2002; Nahapiet \& Ghoshal, 1998; Wasserman \& Faust, 1994), both views may complement each other. This should be true in particular with respect to the generation of new knowledge that calls for both information about opportunities and solid cooperation.

The generation of new knowledge first requires opportunities to access knowledge, that is, whether it is possible to draw upon and engage with the existing and differing knowledge and the activities of various parties (Gabbay \& Zuckerman, 1998; Moran \& Ghoshal, 1996). According to Granovetter (1973), knowledge diffusion occurs by bridging weak ties, that is, by weak ties that connect different social circles and thus provide people with access to information and resources beyond those available in their own social circle. It suggests that the specific configuration of networks (a person's position within a greater social structure) creates information and control benefits. Individuals with networks that include many structural holes (Burt, 1992) or individuals who occupy a peripheral position in a network (Perry-Smith \& Shalley, 2003) have more opportunities to come up with new ideas because they connect people with diverse perspectives, different outlooks, varying interests, and diverse approaches to problems (Ibarra, 1992; Lin et al., 1981; Lincoln \& Miller, 1979).

The generation of new knowledge also requires that the parties engaged in an exchange and combination will be able to recognize the value of new knowledge and to realize some new value created by their engagement (Reagans \& Zuckerman, 2001). Friedkin (1980) points to the strength of strong ties for value recognition by proposing that "macro integration can be based on weak ties which permit episodic transmissions of information among groups, while micro integration is based on a cohesive set of strong ties which permit regular transmissions within groups." (p. 421) Granovetter (1983) adds to the strength of strong ties for value realization: "strong ties have greater motivation to be of assistance and are typically more easily available." (p. 209) All this suggests that the motivation and the ability of close exchange partners create solidarity benefits (Adler \& Kwon, 2002). Exchange partners who trust each other and share competencies and expertise are in the best position to recognize knowledge and to create value: They understand each other, exchange tacit information, show a higher willingness to take risks, and have greater openness (Nahapiet \& Ghoshal, 1998).

The former arguments suggest a division of labor between weak network architectures and strong ties in the creation of innovation. Weak network architectures provide the bridges over which innovations cross the boundaries of social groups. However, the final decision making is influenced mainly by the strong ties to exchange partners. Weimann's (1980) study of an Israeli kibbutz with 280 members specifies that, in situations where actors have either 
strong ties or weak network architectures, strong ties may be preferable with respect to innovation. He shows that only strong ties lead to swift, reflected actions because information moves faster and is more credible. This implies that weak network architectures without strong ties have no value: They do not lead to any action. Further, it follows that strong ties without weak network architectures have at least some value: They lead to actions, even though these actions may not be radically new.

Hypothesis 1. Individuals with strong ties and weak network architectures (structural holes and a peripheral network position) come up with the most innovative solutions. Individuals with strong ties and strong network architectures ${ }^{2}$ come up with more innovative solutions than individuals with weak ties and weak network architectures.

As demonstrated, research that contrasts Coleman with Burt sometimes reasons that networks consisting of strongly interconnected elements are counterproductive for innovation because they contain strong pressure to conform to group norms. A prominent example for strong group norms preventing innovation is the Not-Invented-Here syndrome (Katz \& Allen, 1982). It has led to the assumption that, with regard to innovation, "openness" may be better compared to "closeness." Relying on this conclusion, one could expect that hypothesis 1 is also confirmed for network closure: In particular, dense networks consisting of strong ties prevent innovation.

However, network closure is created within groups and not as structural holes or a peripheral position beyond groups (Burt, 2001). Formalizing the idea of structural embeddedness with the concept of network closure can result in an "oversocialization" of behavior. Individuals are assumed to behave "atomized" as blindly obedient to group norms while opportunities of a wider social structure are neglected (Granovetter, 1985). Consequently, network closure insufficiently describes the structural embeddedness of individuals and allows neither the implication about the amount of norm pressure imposed on actors nor one about possible bridges over which innovations may cross the boundaries of social groups. ${ }^{3}$ Therefore, it is not expected that actors who are embedded in networks

\footnotetext{
${ }^{2}$ Strong network architecture refers to networks that include few structural holes or to individuals who do not occupy a peripheral position in a network.

${ }^{3}$ Networks within groups, be they weak or dense, offer few opportunities to access radical new knowledge. The probability to build local bridges (i.e., information cannot circle within the group if the person is removed) is low. Group members know each other because there is a tendency of one's friends' friends to be one's friends as well (Granovetter, 1973). If group members do not interact with each other, for example, in groups with weakly interconnected actors, they will at least know from each other and information indirectly reaches them via common acquaintance.
} 
consisting of strongly interconnected elements (in dense social groups consisting of strong ties) have disadvantages with respect to knowledge creation.

Hypothesis 2. Individuals with strong ties and strong network closure have no disadvantages with respect to the creation of innovative solutions.

Hypotheses 1 and 2 refer to independent concepts of embeddedness. The embeddedness in a wider social structure (Hypothesis 1) is conceptually different from the embeddedness in focal groups (Hypothesis 2). The main message is that the networks of persons embedded in dense focal groups do not automatically lack structural holes or a periphery whereas the networks of persons embedded in less dense focal groups do not automatically contain many structural holes or are located in the periphery of a wider social structure.

\section{Method}

\subsection{Sample}

In year 2003, I collected a snowball sample of inventors from the German automotive industry. ${ }^{4}$ Relying on MIMOSA, ${ }^{5}$ a software package of the European Patent Office (EPO), the snowball method was applied in five steps and was limited to patent activities from 1991 to 2002. It started with collaboration patents of large German automotive firms, namely, Daimler, BMW, Porsche, Volkswagen, Opel, and Audi. From these patents, I collected all further patents in which the listed inventors were involved. After five steps, it led to a total number of 9,941 inventors involved in 13,416 patents. I extracted the largest component of the patent collaboration network among these inventors, which allowed me to calculate measurements on network architecture. The network consisted of 1,788 inventors (see figure 1). Of these inventors, 515 were identified in the first four steps; that is, I have complete data on their direct patent collaboration partners. The 515 inventors constitute the study

\footnotetext{
${ }^{4}$ Patent data are only appropriate measurements for knowledge outcomes in industries strongly relying on intellectual properties and are industry-specific (Harhoff \& Reitzig, 2001; Michel \& Bettels, 2001). I interviewed patent examiners to select an appropriate industry and choose the German automotive industry for the following reasons: First, in some technological areas (e.g., motor, drive train, mechatronics), the industry has been very innovative over the last decades and thus heavy relies on patents. Second, the German automotive industry only consists of a few major players. It allowed me to find a representative starting point for the snowball method. I interviewed the managers of a spin-off of these major players. It was supported that many innovations are developed in collaboration among the major firms. As the sample starts from collaborative patents, there is a high probability of including important technological inventions. One patent examiner reviewed the final sample. He validated that it includes technologies that should be protected by patents.

${ }^{5}$ MIMOSA offers a range of functions for building, submitting, and saving queries on patents. I additionally cooperated with the Swiss Federal Institute of Intellectual Property. They helped us to collect the massive amount of patent data in the fifth step of the snowball sample.
} 
population. ${ }^{6}$ Using the technology classes of the patents of the 9,941 inventors, I validated whether the patents of the 515 inventors mirrored the population of all patents. There were no significant differences.

Figure 1 about here

In year 2003, I also contacted the 533 inventors by telephone. Of the 533, 147 were subsequently excluded from the sample because of movement, pension, death, or retirement. Overall, 386 inventors were usable for the analysis and were asked to participate in a survey. Of those surveyed, 142 returned completed questionnaires, yielding a response rate of 36 percent. On the basis of different indicators (the technology classes, firm affiliation, application date of a patent, number of EP patents per inventor, and the answer date), ${ }^{7}$ I examined whether the return rate mirrored the selected sample. The differences between participants and nonparticipants were not significant. The participants, on average, had 24 years of work experience, 19 years with the same company, and 11 years in the same division. They spent, on average, 40 percent of their working time on scientific and laboratory tasks, and, in 2003, each respondent published eight scientific papers, was involved in 20 patents, and two nondisclosures. They worked for 31 different companies with the biggest group working for Daimler AG.

Patent collaboration data and survey data were collected to measure the social capital of inventors at time $t$. These data were subsequently combined with indicators measuring the innovativeness of the interviewed inventors at time $t+1$ or from 2004-2009. To measure innovativeness, I relied on patent citations explaining the large time lag in the data. In 2010, I measured whether and how often patents granted after the survey were cited by following inventions. Before collecting patent data on each inventor, I investigated whether the inventor still worked for the same company, ensuring that the patents were invented within the work

\footnotetext{
${ }^{6}$ Seventeen of the inventors identified in the first four stages were excluded because they were not a part of the main component.

${ }^{7}$ I used a classification system for automotive patents that I developed in cooperation with industry experts and the patent examiner. The classification system uses the technology classes of patents but assigns each class to content-related categories. It helps to overcome the problem that patent classifications evolve over time, thus they are not always logically constructed. The original sample and response sample contain the following technologies: Components \& Mechatronics (sample: $32.8 \%$, response: $41.3 \%$ ), Motor \& Drive (sample: $27.7 \%$, response: $19.2 \%$ ), Landing Gear (sample: $13.8 \%$, response: $16.6 \%$ ), Car Inner Room (sample: $14.0 \%$, response: $11.5 \%$ ), Car Body (sample: $10.10 \%$, response: $8.9 \%$ ), Special Vehicles (sample: $1.63 \%$, response: $2.55 \%$ ). In the response sample, Components \& Mechatronics are weakly overrepresented, whereas Motor \& Drive is weakly underrepresented. On an overall level, the included technologies of both samples are not significantly different.
} 
context of 2003. In year 2009, 95 percent of the included inventors still worked for the same company.

\subsection{Dependent measurements to capture innovativeness}

Consistent with prior research, I used patent data to measure the novelty of inventor ideas (see, e.g., Balconi et al., 2004; Harhoff et al., 2003; Trajtenberg, 1990). Patents are direct outputs of industrial $\mathrm{R} \& \mathrm{D}$ and mirror the cumulative process of technological change. A problem with simple patent counts is that a small fraction of patents mostly accounts for the largest part of the value (Griliches, 1990; Harhoff et al., 2003). The literature therefore relies on patent citations to evaluate whether the contributions protected by a patent are more radical or more incremental (Narin, 1994; von Wartburg et al., 2005). When applying for a patent, the assignee has to prove the novelty, nonobviousness, and usefulness of the invention. For this reason, both the inventor and a patent examiner, who has prior knowledge in the respective technological field, compare the invention. The patent application references the relevant sources for judging novelty and inventive steps. Patent citation analyses can be based either on "backward" measures (derived from the citations made by a patent) or on "forward" measures (derived from the citations that a patent subsequently receives from other patents). Forward citations have been identified as an appropriate measure of technological impact (Ahuja \& Lampert, 2001; Henderson \& Cockburn, 1994; Nerkar, 2003). Backward citations, which are often excluded in the patent citation literature, measure the integrated knowledge base (Fleming \& Sorenson, 2001; Jaffe et al., 1993). In the following, both measurements are used to evaluate whether the contributions of inventors protected by patents are more radical or incremental.

Before introducing the patent citation measurements, it has to be mentioned that, like all citation measurements (Frey \& Rost, 2010), patent citations have several drawbacks and should be interpreted as incomplete measurements of innovativeness (Griliches, 1990; Marx et al., 2009; Pavitt, 1985). ${ }^{8}$ This research relies on patent citations because, first, there is no alternative complete measurement of individual innovativeness. Second, for European patents where an independent authority, such as the patent examiner (von Wartburg et al., 2005), cites prior art, there is less reason to expect that the measurement errors of patent citation data are systematically correlated with the social capital of inventors. Third, in contrast to the citations of scholars, I am not aware that patent citations have an incentive effect that promotes

\footnotetext{
${ }^{8}$ In particular, not all inventions are patented. Firms may also decide to exploit intellectual property by other measures, such as keeping it secret or enforced copyright (Hall et al., 2001). Further, patent citation analyses assume that experts in the field comprehensively evaluate the processes, which is not always the case.
} 
strategic behavior. For example, in Germany, employed inventors are paid in proportion to the economic benefit of their patents. Economic success, however, is different from patent citations, which capture the aspects of the technological progress of inventions. Nevertheless, I validated whether the patent citations of inventors in the time prior to the survey, 1998 to 2002 , mirrored their subjective evaluations on the innovativeness of their prior projects. ${ }^{9}$ The results supported significant correlations between backward and forward patent citations and subjective evaluations of innovativeness (for both: $\mathrm{r}=.23 * * *$ ). The correlation, however, was rather small, demonstrating that patent citations do not capture all aspects of individual innovativeness.

Forward citations. Forward citations are the number of citations received by a patent. Counting the forward citations of patents shows whether patented inventions are mentionedeither by examiners (as entities of prior knowledge confining the scope of claims) or by applicants or their lawyers (as an indication of prior art that is extended by the invention) when an inventor files for a new patent. Because they are a paper trail of codified knowledge (Jaffe et al., 1993), forward citations are considered an appropriate measure for technological impact, defined as an invention's impact on subsequent technological progress (Albert et al., 1991; Nerkar, 2003). To measure sustainable technological progress, for each inventor, I counted how many citations that inventor's patents, invented after the survey, received from subsequent inventions. ${ }^{10}$ I relied on the period from 2004 to 2009 to ensure that there was ample time for the citation of the patents. I did not correct the measurement with regard to a patent's likelihood of being cited due to membership in a certain cohort (e.g., denoted by its priority or publication year, see Dahlin et al., 2004) because all inventions were from the same time period and all the inventors from the same industry. However, I did control for

\footnotetext{
${ }^{9}$ Respondents assessed the average product innovativeness in their projects during the last years $(1=$ below $20 \%$ of projects were new/ very radical; $5=$ over $80 \%$ of projects were new/ very radical). The scale included 12 items (Danneels \& Kleinschmidt, 2001; Salomo, 2003). Six items measured dimensions of market familiarity, that is, to what degree the products were new from a market point of view. Included items were new customers for the firm, new competitors for the firm, a new array of products for the firm, new customer benefits for the branch of industry, a change in consumer attitudes for the branch of industry, and high changeover costs for the branch of industry. Six items measured dimensions of technology familiarity, that is, to which degree the products were new from a technological point of view. Included items were new technological solutions for the firm, performance improvements for the firm, new knowledge for the firm, new technological solutions for the branch of industry, performance improvements for the branch of industry, and new knowledge for the branch of industry. The scale showed a good reliability, that is, $\alpha=.856$.

${ }^{10}$ Citation data were gathered from PatBase (www.patbase.com). PatBase covers over 30 million patent families from the U.S., EP, PCT, GB, DE, and FR patent-issuing authorities from over 75 countries with historical information dating back to the early 1900s. The database is grouped into extended patent families with each unique invention representing one consolidated family. Grouping all equivalents of an invention eliminates the danger of counting the same invention multiple times in the data set. On the family level, the database offers citation counts, that is, the number of backward and forward citations per patent. The patents of each inventor were manually validated by using postal addresses and names of employers.
} 
characteristics of the specific technological area in which inventors work (see control variables).

Backward citations. Backward citations are citations made by a patent to a previously issued patent. Studies using backward citation information investigated spillovers, called "knowledge flows," between technology classes (Rosenkopf \& Nerkar, 2001; Trajtenberg et al., 2002) or geographic regions (Jaffe et al., 1993; Tijssen, 2001). Other studies used backward citations as a means to analyze the localness of a technological search by organizations (Fleming \& Sorenson, 2001; Podolny \& Stuart, 1995). In general, a high number of backward citations shows that the invention is closely linked to relevant prior art and thus contributes to technological process (von Wartburg et al., 2005). For each inventor, I counted how many inventions were mentioned in that inventor's patents that were invented after the survey (2004-2009).

\subsection{Independent measurements to capture social capital}

I collected patent collaboration data for 1991 to 2002 to measure the embeddedness of inventors in broader inventor networks (see Figure 1). I also collected egocentric network data for year 2003 to measure relationship quality and ego network closure. Egocentric networks select relevant exchange partners, called Alteri, from all contacts of a person, called Ego. To select relevant exchange partners, the method uses name generators. The respondents quote their network partners via name codes. I used name codes to identify exchange partners and to collect additional information about personal attributes or the kind of relationship. The egocentric method used in this study applies 10 name generators to identify work-related network partners of inventors. The literature suggests using multiple questions because people with a larger number of contacts are more likely to respond (Burt, 1997a). The wording of the name generators is listed in Table 1. Questions were developed by using prior studies on egocentric networks (Burt, 1992, 1997a). I adapted these questions to innovation topics (Hansen, 1999; Hauschildt \& Gemünden, 1998).

Table 1 about here

The instrument was pretested in a spin-off company of a major German automotive firm. The company employs 111 R\&D employees in eight business units. I asked two employees, one department manager from each unit and the CEO, about their egocentric networks. In contrast to the final study design, the instrument was applied nonanonymously to investigate its appropriateness in capturing collaboration networks. I additionally asked each 
Ego about the relationships between its Alteri. Figure 2 shows the resulting networks of the 26 people. Overall, the 26 people named 184 different Alteri in their work-related contact networks, indicating that the instrument collects information on the expanding networks of actors. Sixty-three of the Alteri work in the same company indicating that more than 50 percent of the employees were named. I presented the resulting network to those interviewed, and there was overall agreement that I had measured important work-related exchanges in the firm. In year 2003, the egocentric instrument was applied to the snowball sample. In total, it identified 1,905 job-related network partners of the 142 respondents. The average number of persons named in the different name generators is documented in Table 1.

Figure 2 about here

In the following, a theoretical model and an empirical measurement model are introduced to measure tie strength, ego network closure, structural holes, and a peripheral network position. The theoretical model exclusively relies on proxies that the social network literature has introduced to measure the different network concepts. The empirical model builds on the results of a factor analysis (see Table 2), that is, on empirically extracted dimensions that capture different aspects of networks. In contrast to the theoretical model, the empirical model has the advantage that multicollinearity-a major problem in network studies - is reduced. It has, however, the disadvantage that it additionally includes network variables that are normally not used to represent the constructs tie strength, ego network closure, structural holes, and peripheral network position. In the following, both alternative measurement approaches are used to predict innovativeness. The empirical measurement model is discussed in more detail because multicollinearity problems are smaller and construct validity may be improved by using many proxies.

Table 2 about here

Strength of ties. In the empirical model, tie strength is operationalized by eight items that describe the relationship quality between Ego and each Alter. Contact frequency shows how frequently Ego and Alter have contact with each other (1=irregularly, 2=monthly, 3=weekly, 4=daily, 5=several times a day). Emotional closeness between Ego and Alter is measured by trustworthiness, that is, whether Ego trusts Alter with essential project details almost blindly ( $1=$ is not true through $5=$ is true) and sure handedness/reliability, whether Alter keeps promises ( $1=$ never through $5=$ always). Cognitive closeness between Ego and Alter is 
measured by the proximity in professional backgrounds (1=very different through $5=$ very close), the overlap of technological knowledge ( $1=$ very low through $5=$ very high), and subjective evaluations of creativity/innovativeness ( $1=$ not innovative/creative through $5=$ very innovative/creative). Finally, two items capturing the amount of resource access also show high factor loadings. The first item measures the hierarchical position of each Alter $(0=$ lower hierarchical position, 1=same hierarchical position, $2=$ higher hierarchical position) and the second item or the level of training and education (1=apprenticeship through $5=\mathrm{PhD})$. The eight items show a good reliability, $\alpha=.92$. I built a final measurement of ties strength by calculating the mean value of the eight items and standardized the new variable so that the maximum amounted to one.

In the theoretical model, tie strength is operationalized by contact frequency, trustworthiness, and sure handedness. The three items showed good reliability, $\alpha=.81$.

Ego network closure. In the empirical model, ego network closure is measured by ego network size and exchange multiplexity, as identified in the egocentric method. The pretest showed that both measurements could be used to capture ego network density (see Figure 3). ${ }^{11}$ Small ego networks with high exchange multiplexity are typically denser than large ego networks with low exchange multiplexity. Ego network size indicates how many Alteri were named by Ego. I counted the reverse value, that is, higher numbers indicate smaller networks, and I standardized the new variable so that the maximum was one. Exchange multiplexity counts how often an Alter is named by Ego in different exchanges, that is, in different name generators (Burt, 1997b). For each Ego, I calculated the average multiplexity of the relationships, indicating the average number of exchange contents that are shared with an Alter. Exchange multiplexity again was standardized with a maximum of one. Finally, I built a new additive measurement of ego network closure where a maximum of one indicates small, multiplex networks.

Figure 3 about here

\footnotetext{
${ }^{11}$ The completion of the Alter-Alteri relationship matrix is very time-consuming. I therefore decided to drop this matrix from the final questionnaire.
} 
In the theoretical model, ego network closure is measured by Ego's network density in patent collaboration networks. Ego network density captures the amount of realized collaborations with all possible coinventors. ${ }^{12}$

Structural holes. In the empirical model, structural holes were measured by the size of and the constraint in patent collaboration networks. Inventors who collaborated with many different persons who did not collaborate with other of Ego's alters are assumed to have networks rich in structural holes. The size of patent collaboration networks measures how many different inventors a person collaborated with via patents from 1991 to 2002. The measurement was standardized so that the maximum was one. The constraint in patent collaboration networks was measured with Burt's adjustment of constraint (Burt, 1992). It measures the extent to which Ego is invested in people who are invested in other of Ego's alters. I counted the reverse value (the higher numbers indicate networks without constraint) and standardized the new variable so that the maximum was one. Finally, I built a new additive measurement of structural holes where the maximum of one indicates large networks without constraint.

In the theoretical model, structural holes are operationalized by Burt's adjustment of constraint.

Peripheral position. In the empirical model, a peripheral network position is measured by an actor's closeness centrality in patent collaboration networks and the amount of contacts outside the company. Inventors who have a low closeness centrality in patent collaboration networks and a low amount of external contacts are assumed to have peripheral network positions (see also Perry-Smith, 2006). The closeness centrality measures the mean geodesic distance (the shortest path) between an actor and all other actors in the patent collaboration network reachable from it (Wasserman \& Faust, 1994). The variable was standardized so that the maximum was one. The amount of external contacts was calculated from the ego network survey and indicates Ego's investments in contacts outside the company. I built a new additive measurement of peripheral network position where smaller values indicate peripheral actors with few external ties and larger values indicate central actors with many external ties.

In the theoretical model, a peripheral network is operationalized by an actor's closeness centrality in patent collaboration networks.

\footnotetext{
${ }^{12}$ Patent collaboration networks contain a high proportion of weak ties that can contaminate the validity of the density measurement. The density measurement of the empirical measurement model may be therefore more suitable.
} 


\subsection{Control measures}

Technological area. I controlled for characteristics of the specific technological area in which inventors work. I measured the speed of technological change (1=fast technological changes through $7=$ slow technological improvements) and the availability of knowledge (1=few documented technological knowledge through $7=$ fast growing amount of technological knowledge). For inventors working in slow-changing technological areas that include less documented knowledge, the exploration of new knowledge may be easier (Henderson, 1996).

Personal characteristics. I controlled for the personal characteristics of inventors. First, their job engagement was included. The scale consists of 15 items measuring the (selfevaluated) organizational citizenship behavior of the interviewed persons with respect to innovation-related behavior (Hauschildt \& Gemünden, 1998), for example, knowledge support or gate-keeping ( $1=$ no engagement to $5=$ high engagement). The items show a good reliability, $\alpha=.866$. For every participant, I calculated the mean value of the 15 items. According to the literature, organizational citizenship behavior improves certain performance indicators in firms (Podsakoff et al., 1997). Second, for each inventor, I measured the hierarchical position ( $1=$ subordinate through $5=$ executive), the highest education level (1=apprenticeship through $5=\mathrm{PhD})$, and the work experience in years. All items are indicators of the amount of competences and resources of inventors facilitating the creation of new knowledge.

Patent characteristics. Finally, on the patent level, I controlled for the number of patents, the average number of involved inventors, and the average priority year. Inventors involved in many patent applications have a higher probability of being cited. Further, a larger number of inventors per patent indicates greater competence behind the invention, and, ultimately, a higher likelihood of a patent being cited as relevant prior art (Gittelman \& Kogut, 2003; Rost, 2006; Wuchty et al., 2007). Finally, older patents have a higher likelihood of being cited (Gittelman \& Kogut, 2003; Lettl et al., 2009).

Table A-1 in the appendix documents the descriptive statistics and the correlations of the included variables.

\subsection{Statistical method}

I relied on a negative binomial regression rather than an OLS regression because the dependent variable (number of patent citations) cannot be less than zero (Gittelman \& Kogut, 2003; Nerkar, 2003; Sorenson \& Fleming, 2004). Further, the distribution of patent citation 
counts is skewed because a small number of patents in a given technological field regularly account for the majority of forward or backward citations (Scherer \& Harhoff, 2000).

For all network measurements, I additionally included the quadratic term. As shown in prior research, social capital contains benefits and risks implying that benefits cannot maximize ad infinitum; at a certain point, risks prevail (Adler \& Kwon, 2002; Perry-Smith \& Shalley, 2003).

\section{Results}

\subsection{Results by using the empirical measurement model of social capital}

Tables 3 and 4 document the regression results predicting the knowledge base (backward citations) and the technological impact (forward citations) of patents invented in the time period after the survey by using the empirical measurement model. The regression models are computed in four steps. First, I included the control variables, second the linear effects of network measurements, third their quadratic effects, and fourth the interaction effects of network architecture and ties strength.

Table 3 and 4 about here

The findings first indicated that all network measurements exerted no linear effects on innovativeness (see column II, Tables 3 and 4). Effects are significant if quadratic effects are included. In line with former research, the findings support inverted u-shaped relationships between social capital and innovativeness suggesting that inventors with balanced social capital investments come up with the most innovative solutions. The results also show that inventors acting in networks rich in structural holes, but not so rich that a person can act completely autonomously, and inventors with a peripheral network position, but not so peripheral that other actors cannot be reached, integrate most prior knowledge (backward patent citations, see column III, Table 3). Further, the inventions of persons embedded in close ego networks, but not so dense that exchanges become too redundant, and the inventions of persons with a peripheral network position, but not so peripheral that other network actors cannot be reached, have the highest impact on future technological knowledge (forward patent citations, see column III, Table 4).

Second, the findings indicated that tie strength interacts with network architecture. The interaction with structural holes (Table 3, column IV) and the interactions with structural 
holes and peripheral network position (Table 4, column IV) are significant. ${ }^{13}$ I found no significant interactions with network closure. Figure 4 illustrates the significant findings and shows the marginal effects of network architecture on innovativeness for inventors with strong relationships to their core exchange partners (calculated for one standard deviation above the mean value of ties strength) and inventors with weak relationships to their core exchange partners (calculated for one standard deviation below the mean value of ties strength). The figure additionally includes significant human capital indicators to illustrate the magnitude of social capital effects.

Figure 4 about here

According to Figure 4, inventors who combine strong ties to their exchange partners with structural holes in their broader networks integrate a larger knowledge base of prior technologies (backward citations), and their inventions get cited more often by following inventions (forward citations) compared to inventors who combine weak ties with structural holes. The amount of structural holes should be not too high because of diminishing returns. For example, the patents of inventors having stronger relationships with their exchange partners and a medium amount of structural holes account on average for 34.8 backward and 6.7 forward citations. In contrast, the patents of inventors having weaker relationships with their exchange partners and a medium amount of structural holes account on average for 3.8 backward and 0.06 forward citations. Stronger ties are also more beneficial than weaker ties if network architectures consist of a suboptimal amount of structural holes. The patents of inventors with stronger relationships and no structural holes account on average for 6.0 backward and 4.1 forward citations, whereas the patents of inventors with weaker relationships and no structural holes account on average for 1.0 backward and 0.05 forward citations. Further, the patents of inventors with stronger relationships and a maximum of structural holes account on average for 1.7 backward and 1.1 forward citations, whereas the patents of inventors with weaker relationships and a maximum of structural holes account on average for 0.9 backward and 0.00 forward citations. The last results also demonstrate that with respect to innovation a lower, and not a higher, amount of structural holes is more beneficial.

\footnotetext{
${ }^{7}$ I also ran robustness tests by including only significant effects of the regression results in columns IV. It did not change the results.
} 
The regression analysis predicts similar effects for peripheral network positions. The patents of inventors, who combine stronger ties to their exchange partners with a peripheral network position in their broader networks, are cited more often by following patent submissions (forward citations) compared to inventors who combine weak ties with a peripheral network position. For example, the patents of inventors having stronger relationships with their exchange partners and occupying decentral, but not too peripheral, network positions account on average for 4.1 forward citations. In contrast, the patents of inventors having weaker relationships with their exchange partners and occupying the same network positions account on average for 1.0 forward citations. The results further indicate that with respect to network centrality stronger ties are not always superior. Strong ties pay off for persons occupying a peripheral network position. However, if inventors move in the center of networks, weak relationships become more advantageous. For example, the patents of inventors having weaker relationships with their exchange partners and occupying more central, but not too central, network positions account on average for 1.4 forward citations. In contrast, the patents of inventors having stronger relationships with their exchange partners and occupying the same network positions account on average for 1.2 forward citations. Even though the differences are small, the findings indicate the advantages of weak ties for central actors and the advantages of strong ties for peripheral actors.

Finally, a comparison of social capital with human capital allows one to imagine the magnitude of the former effects. In the regression model, predicting backward citations of the human-capital-indicator work experience was positive and significant. Persons with a maximum of work experience integrated 22.3 prior technologies in their inventions, whereas persons with a minimum of work experience integrated 7.9 prior technologies. In comparison, persons with strong ties and an optimal amount of structural holes integrated 34.8 prior technologies in their inventions, whereas persons with weak ties and a maximum of structural holes integrated 0.09 prior technologies. Social capital investments thus exert more distinct effects on the breadth of integrated knowledge than human capital investments.

In the regression model that predicted forward citations, the highest level of education of the inventors was positive and significant. Patents of persons holding a $\mathrm{PhD}$ were cited 4.9 times by following technologies, whereas the patents of persons with an apprenticeship were cited 0.9 times. In comparison, the patents of persons with strong ties and an optimal amount of structural holes accounted for 6.7 forward citations, whereas the patents of persons with weak ties and a maximum of structural holes accounted for 0.00 forward citations. Further, the patents of persons with strong ties and a more peripheral network position accounted for 
4.1 forward citations, whereas the patents of persons with weak ties and a maximum of decentrality with strong ties plus a maximum of centrality accounted for 0.00 forward citations. All this suggests that social capital investments have equal or even more pronounced effects on the technological impact of generated knowledge than human capital investments.

\subsection{Results by using the theoretical measurement model of social capital}

Finally, a test was made to determine whether the results were stable if the theoretical measurements of social capital were used. Table 5 and Figure 5 document the results. The findings again indicate that tie strength interacts with network architecture. With respect to backward patent citations, the interactions of tie strength with structural holes and peripheral network position are significant. With respect to forward patent citations, the interaction of tie strength with structural holes is significant. Again, there is no significant interaction of tie strength with network closure even though a different measurement is applied. Figure 5 illustrates the significant findings. It shows that inventors who combined strong ties to their exchange partners with structural holes in their broader networks integrated a larger knowledge base of prior technologies (backward citations), and their inventions were cited more often by following inventions (forward citations) compared to inventors who combined weak ties with structural holes. In contrast to the former findings, structural holes have no diminishing returns on forward citations. With respect to peripheral network positions, I found no significant results for forward citations, but I did for backward citations. However, the discovered relationship is similar to the former one. The patents of inventors who combined stronger ties to their exchange partners with a peripheral network position in their broader networks integrated a larger knowledge base of prior technologies (backward citations) compared to inventors who combined weak ties with a peripheral network position. The results again indicate that with respect to network centrality stronger ties are not always superior. Strong ties pay off for persons occupying a peripheral network position. If persons move in the center of networks, weak relationships become more advantageous.

Table 5 and Figure 5 about here

\subsection{Conclusion from the empirical results}

The empirical findings support strong ties to exchange partners as a prerequisite for the creation of innovation. A combination of strong ties with a certain amount of structural holes 
or in particular a more peripheral network position facilitates innovation. According to the findings, weak ties are only beneficial if actors occupy a more central network position. The advantages of weak ties in centralized networks seem to be smaller or more risky than the advantages of strong ties in decentralized networks. I therefore conditionally accept hypothesis 1: It has been hypothesized that individuals with strong ties and weak network architectures (structural holes and peripheral network positions) come up with the most innovative solutions and that individuals with strong ties but without weak network architectures come up with more innovative solutions than individuals without strong ties but with weak network architectures. The empirical results further show no evidence that network closure significantly interacts with tie strength. I conditionally accept hypothesis 2 . It has been suggested that actors who are embedded in networks consisting of strongly interconnected elements (in dense social groups consisting of strong ties) have no disadvantages with respect to knowledge creation.

\section{Conclusion}

This research contrasted two alternative views on social capital. Although Coleman's view pays attention to the quality of relationships (tie strength), Burt's view pays attention to the structural configuration of relationships (structural holes). Most former research assumes a trade-off between both views. I show that instead of being substitutes Burt complements Coleman. I point out the strength of strong ties in the creation of innovation. Strong ties ensure solidarity benefits that are important for the tacit characteristics of innovations, that is, knowledge recognition and realization. Strong ties however become most beneficial when combined with weak network architectures. Weak network architecture, such as networks including some structural holes (however not too many) or decentralized network positions (however not too peripheral), offer information and control benefits important for opportunity seeking (knowledge access). Therefore, actors invested in strong ties and embedded in weak network architectures come up with the most innovative solutions: They are able to recognize and realize the value of accessed knowledge.

The findings in particular point out that innovation research tends to overestimate the impact of weak network architecture in the creation of innovation. First, the information and control advantages of weak network architectures are only beneficial if actors are able to recognize and realize the underlying value. Value recognition and realization requires strong social ties. Weak network architectures thus can only constitute a side condition multiplying the existing solidarity benefits of strong relationships. Second, the weakest network architectures do not offer the highest information and control benefits. Structural holes or 
peripheral network positions have diminishing returns, suggesting that balanced network architectures are superior. Third, the same conclusion holds with respect to tie strength. As indicated by the regression results in Column IV of Tables 3 and 4, tie strength is also an inverted u-shaped relationship to innovativeness. It suggests that, even though stronger ties are more beneficial than weaker ties, ties should not become too strong.

Further, it has been shown that networks consisting of strongly interconnected elements (dense focal groups consisting of strong ties among actors) are not counterproductive for innovation. In theory, it suggests that the difference between Coleman and Burt could be conceptualized better by the concepts of tie strength and weak network architecture, not by the concepts of tie strength and network closure. For managerial practice, it suggests that innovative organizations may consist of dense social circles (e.g., stable work groups) or open social circles (e.g., project work groups). What is important is whether employees have the possibility to create strong relationships with some exchange partners and to be embedded in a few bridging relationships beyond their focal work groups.

With respect to further research, the findings may be interesting for the concept of "Open Innovation" (Chesbrough, 2003). Open innovation can be described as combining internal and external ideas as well as internal and external paths to advance the development of new technologies. In recent years, many companies have shifted from so-called closed innovation processes toward a more open way of innovating, for instance, through cooperation with suppliers and competitors or through active searches for new technologies and ideas outside of the firm. Although the results confirm the basic idea of combining closed innovation principles with open innovations principles for competitive advantages, they also point out some caveats. First, open innovation will not work if closed innovation principles are pushed back. Second, in particular, balanced open innovation principles may be beneficial. A similar conclusion was drawn some years ago by Slappendel (1996). Research can analyze both conditions in more detail. It may prevent open innovation from turning into a management fashion that enacts the realities that it describes but is unable to fulfill its promises (Callon, 2007).

This research has several limitations that are important when interpreting the empirical results. First, patent data are incomplete measures of individual innovativeness. Even though there is validation that patent citations capture some aspects of innovativeness, they do not capture all aspects. Second, the study sample is rather small, implying less precise estimates. Even though I am optimistic that a larger sample would result in similar conclusions, this has to be validated. Third, the patent citation counts used in this study relied on single-stage 
citation information. Yet, other studies used multistage citation analyses and bibliographical coupling to assess the technological importance or the "basicness" of inventions (Trajtenberg et al., 2002; von Wartburg et al., 2005). Multistage citation analyses and bibliographical coupling may offer more precise measures of knowledge creation by considering path dependency.

\section{Acknowledgements}

I am grateful for the help of Thorsten Teichert (professor of marketing and innovation management, University of Hamburg), Iwan von Wartburg (former assistant professor, University of Hamburg, founder and owner of iploit ag), Harald Pier (former patent examiner, Swiss Federal Institute of Intellectual Property), Alfred Krappel (key inventor of the automotive industry, serial production and Formula 1), Katharina Valta and Lukas Frösch (graduates, University Bern), Roger Lüthi (Phd student, University Zurich), Hans-Georg Gemünden (professor of innovation and technology management, TU Berlin), Diether Gebert (professor of organization and administrative management, TU Berlin), Gino Cattani (professor of management and organization, New York University), the employees of Inpro $\mathrm{GmbH}$ (acceleration of technological innovation in the automotive industry), and the participants of the EGOS sub-group "The Social Side of Creativity: Networks, Audiences and Rewards". I further thank for the most helpful comments by two reviewers of Research Policy and by the editor Michel Callon. Finally I thank Patricia A. Cunkelman for English editing. 


\section{References}

Adler, P. S. \& Kwon, S. W., 2002. Social capital: Prospects for a new concept. Academy of Management Review 27, 17-40.

Ahuja, G. \& Lampert, C. M., 2001. Entrepreneurship in the large corporation: A longitudinal study of how established firms create breakthrough inventions. Strategic Management Journal 22, 521-543.

Albert, M. B., Avery, D., Narin, F., \& P., M., 1991. Direct validation of citation counts as indicators of industrially important patents. Research Policy 20, 251-259.

Amabile, T., 1996. Creativity in context. Westview Press, Boulder.

Balconi, M., Breschi, S., \& Lissoni, F., 2004. Networks of inventors and the role of academia: An exploration of italian patent data. Research Policy 33, 127-145.

Burt, R. S., 1992. Structural holes: The social structure of competition. Harvard Business School Press, Cambridge.

Burt, R. S., 1997a. The contingent value of social capital. Administrative Science Quarterly 42, 339-365.

Burt, R. S., 1997b. A note on social capital and network content. Social Networks 19, 355373.

Burt, R. S., 2001. Structural holes versus network closure as social capital, in: Lin, N., Cook, K. S., Burt, R.S. (Eds), Social capital: Theory and research. Aldine de Gruyter, New York, pp. 31-56.

Callon, M., 2007. What does it mean to say that economics is performative?, in: Mackenzie, D., Muniesa, F., Siu, L. (Eds), Do economists make markets? On the performativity of economics, Princeton University Press, Princeton, pp. 311-357.

Capaldo, A., 2007. Network structure and innovation: The leveraging of a dual network as a distinctive relational capability. Strategic Management Journal 38, 585-608.

Chesbrough, H. W., 2003. Open innovation: The new imperative for creating and profiting from technology. Harvard Business School Press, Boston.

Chubin, D., 1976. The conceptualization of scientific specialties? Sociological Quarterly 17, 448-476.

Coleman, J., 1988. Social capital in the creation of human capital. American Journal of Sociology 94, 95-120.

Coleman, J., 1990. Foundations of social theory. Harvard University Press, Cambridge.

Cook, K. S., 1977. Exchange and power in networks of interorganizational relations. The Sociological Quarterly 18, 62-82.

Dahlin, K., Taylor, M., \& Fichman, M., 2004. Today's edisons or weekend hobbyists: Technical merit and success of inventions by independent inventors. Research Policy 33, 1167-1183.

Danneels, E. \& Kleinschmidt, E. J., 2001. Product innovativeness from the firm's perspective: Its dimensions and their relation with project selection and performance. Journal of Product Innovation Management 18, 357-373.

Fehr, E. \& Gächter, S., 2002. Altruistic punishment in humans. Nature 415(6868), 137-140.

Fine, G. \& Kleinman, S., 1979. Rethinking subculture: An interactionist analysis. American Journal of Sociology 85, $1-20$.

Fleming, L. \& Sorenson, O., 2001. Technology as a complex adaptive system: Evidence from patent data. Research Policy 30, 1019-1039.

Fleming, L., King, I., C. , \& Juda, A., 2007. Small worlds and regional innovation. Organization Science 18, 938-954.

Freeman, L. C., 1977. A set of measures of centrality based on betweenness. Sociometry 40, $35-40$. 
Frey, B. S. \& Rost, K., 2010. Do rankings reflect research quality? Journal of Applied Economics 13, 1-38.

Friedkin, N., 1980. A test of structural features of granovetter's strength of weak ties theory. Social Networks 2, 411-422.

Gabbay, S. M. \& Zuckerman, E. W., 1998. Social capital and opportunity in corporate R\&D: The contingent effect of contact density on mobility expectations. Social Science Research 27, 189-217.

Gittelman, M. \& Kogut, B., 2003. Does good science lead to valuable knowledge? Biotechnology firms and the evolutionary logic of citation patterns. Management Science 49, 366-382.

Granovetter, M., 1973. The strength of weak ties. American Journal of Sociology 6, 13601380.

Granovetter, M., 1974. Getting a job: A study of contacts and careers. Harvard University Press, Cambridge.

Granovetter, M., 1983. The strength of weak ties: A network theory revisited. Sociological Theory 1, 201-233.

Granovetter, M., 1985. Economic-action and social-structure - the problem of embeddedness. American Journal of Sociology 91, 481-510.

Griliches, Z., 1990. Patent statistics as economic indicators: A survey. Journal of Economic Literature 28, 1661-1707.

Hall, B. H., Jaffe, A. B., \& Trajtenberg, M., 2001. The NBER patent citations data file: Lessons, insights and methodological tools, NBER Working Paper 8498. National Bureau of Economic Research, Cambridge.

Hansen, M. T., 1999. The search-transfer problem: The role of weak ties in sharing knowledge across organization subunits. Administrative Science Quaterly 44, 82-111.

Hargadon, A. \& Sutton, I. R., 1997. Technology brokering and innovation in a product development firm. Administrative Science Quaterly 42, 716-749.

Harhoff, D. \& Reitzig, M., 2001. Strategien zur Gewinnmaximierung bei der Anmeldung von Patenten. Wirtschaftliche und rechtliche Aspekte als Entscheidungsgrößen beim Schutz von FuE. Zeitschrift für Betriebswirtschaft 71, 509-530.

Harhoff, D., Scherer, F. M., \& Vopel, K., 2003. Citations, family size, opposition and the value of patent rights. Research Policy 32, 1343-1363.

Hauschildt, J. \& Gemünden, H. G., 1998. Promotoren - Champions der Innovation. Gabler, Wiesbaden.

Henderson, R. \& Cockburn, I., 1994. Measuring competence - exploring firm effects in pharmaceutical research. Strategic Management Journal 15, 63-84.

Henderson, R. M., 1996. Technological change and the management of architectural knowledge, in: Cohen, M. D., Sproull, L. S. (Eds), Organizational Learning, Sage, Thousand Oaks, pp. 359-375.

Ibarra, H., 1992. Homophily and differential returns: Sex differences in network structure and access in an advertising firm. Administrative Science Quarterly 37, 422-447.

Inkpen, A. C. \& Tsang, E. W., 2005. Social capital, networks, and knowledge transfer. Academy of Management Journal 30, 146-165.

Jaffe, A. B., Trajtenberg, M., \& Henderson, R., 1993. Geographic localization of knowledge spillovers as evidenced by patent citations. Quarterly Journal of Economic 108, 577-675.

Katz, R., \& Allen, T. J., 1982. Investigating the Not Invented Here (NIH) Syndrom. R\&D Management 12, 7-19.

Landry, R., Amara, N., \& Lamari, M., 2002. Does social capital determine innovation? Technological Forecasting and Social Change 69, 681-701. 
Leenders, R., van Engelen, J. M. L., \& Kratzer, J., 2007. Systematic design methods and the creative performance of new product teams: Do they contradict or complement each other? Journal of Product Innovation Management 24, 166-179.

Lettl, C., Rost, K., \& Von Wartburg, I., 2009. Why are some independent inventors 'heroes' and others 'hobbyists'? The moderating role of technological diversity and specialization. Research Policy 38, 243-254.

Lin, N., Dayton, P., \& Greenwald, P., 1978. Analyzing the instrumental use of relations in the context of social structure. Sociological Methods and Research 7, 149-166.

Lin, N., Enseln, W., \& Vaughn, J. C., 1981. Social resources and strength of ties: Structural factors in occupational status atteinment. American Sociological Review 46, 393-405.

Lin, N., 2001. Social capital: A Theory of Social Structure and Action. Cambridge University Press, Cambridge.

Lincoln, J. R. \& Miller, J., 1979. Work and friendship ties in organizations: A comparative analysis of relational networks. Administrative Science Quarterly 24, 181-199.

Marx, M., Strumsky, D., \& Fleming, L., 2009. Mobility, skills, and the michigan noncompete experiment. Management Science 55, 875-889.

McFadyen, M. A. \& Cannella, A. A., 2004. Social capital and knowledge creation: Diminishing returns of the number and strength of exchange. Academy of Management Journal 47, 735-746.

McFadyen, M. A., Semadeni, M., \& Cannella, A. A., 2009. Value of strong ties to disconnected others: Examining knowledge creation in biomedicine. Organization Science 20, 552-564.

Michel, J. \& Bettels, B., 2001. Patent citation analysis, a closer look at the basic input data form patent search reports. Scientometrics 51, 185-201.

Milgram, S., 1967. The small-world problem. Psychology Today 1(5), 62-67.

Moran, P. \& Ghoshal, S., 1996. Value creation by firms. Academy of Management Best Paper Proceedings, 41-45.

Moran, P., 2005. Structural vs. Relational embeddedness: Social capital and managerial performance. Strategic Management Journal 26, 1129-1151.

Nahapiet, J. \& Ghoshal, S., 1998. Social capital, intellectual capital and the organizational advantage. Academy of Management Review 23, 242-266.

Narin, F., 1994. Patent bibliometrics. Scientometrics 30, 147-155.

Nelson, R. E., 1989. The strength of strong ties: Social networks and intergroup conflict in organizations. Academy of Management Journal 32, 377-401.

Nerkar, A., 2003. Old is gold? The value of temporal exploration in the creation of new knowledge. Management Science 49, 211-229.

Pavitt, K., 1985. Patent statistics as indicators of innovative activities: Possibilities and problems. Scientometrics 7, 77-79.

Perry-Smith, J. E., 2006. Social yet creative: The role of social relationships in facilitating individual creativity. Academy of Management Journal 49, 85-101.

Perry-Smith, J. E. \& Shalley, C. E., 2003. The social side of creativity: A static and dynamic social network perspective. Academy of Management Review 28, 89-106.

Podolny, J. M. \& Stuart, T. E., 1995. A role-based ecology of technological change. American Journal of Sociology 100, 1224-1260.

Podsakoff, P. M., Ahearne, M., \& MacKenzie, S. B., 1997. Organizational citizenship behavior and the quantity and quality of work group performance. Journal of Applied Psychology 82, 262-270.

Reagans, R. \& Zuckerman, E. W., 2001. Networks, diversity, and productivity: The social capital of corporate R\&D teams. Organization Science 12, 502-517.

Reagans, R. \& McEvily, B., 2003. Network structure and knowledge transfer: The effects of cohesion and range. Administrative Science Quarterly 48, 240-267. 
Rosenkopf, L. \& Nerkar, A., 2001. Beyond local search: Boundary-spanning, exploration, and impact in the optical disk industry. Strategic Management Journal 22, 287-306.

Rost, K., 2006. Patentstärke und Netzwerkeinbettung in Forscher- und Entwicklernetzwerken. Zeitschrift für betriebswirtschaftliche Forschung 5, 363-389.

Sahlins, M. D., 1972. Stone age economics. Aldine, Chicago.

Salomo, S., 2003. Konzept und Messung des Innovationsgrades - Ergebnisse einer empirischen Studie zu innovativen Entwicklungsvorhaben. In M. Schwaiger \& D. Harhoff (Eds.), Empirie und Betriebswirtschaft: 399-427. Stuttgart.

Scherer, F. M. \& Harhoff, D., 2000. Policy implications for a world with skew-distributed returns to innovation. Research Policy 29, 559-566.

Slappendel, C., 1996. Perspectives on innovation in organizations. Organization Studies 17(1), 107-129.

Smith, K., Collins, C. J., \& Clark, K. D., 2005. Existing knowledge, knowledge creation capability, and the rate of new product introduction in high-technology firms. Academy of Management Journal 48, 346-357.

Sorenson, O. \& Fleming, L., 2004. Science and the diffusion of knowledge. Research Policy $33,1615-1634$.

Subramaniam, M. \& Youndt, M. A., 2005. The influence of intellectual capital on the types of innovative capabilities. Academy of Management Journal 48, 450-463.

Tijssen, R. J. W., 2001. Global and domestic utilization of industrial relevant science: Patent citation analysis of science-technology interactions and knowledge flows. Research Policy 30, 35-54.

Trajtenberg, M., 1990. A penny for your quotes: Patent citations and the value of inventions. RAND Journal of Economics 21, 172-187.

Trajtenberg, M., Henderson, R., \& Jaffe, A. B., 2002. University versus corporate patents: A window on the basicness of invention, in: Jaffe, A. B., Trajtenberg, M. (Eds), Patents, citations and innovations - a window on the knowledge economy, MIT Press, Cambridge, pp. 51-88.

Tsai, W. P. \& Ghoshal, S., 1998. Social capital and value creation: The role of intrafirm networks. Academy of Management Journal 41, 464-476.

Uzzi, B., 1997. Social structure and competition in interfirm networks: The paradox of embeddedness. Adminstrative Science Quarterly 42, 35-67.

Uzzi, B. \& Spiro, J., 2005. Collaboration and creativity: The small world problem. American Journal of Sociology 111, 447-504.

von Wartburg, I., Teichert, T., \& Rost, K., 2005. Inventive progress measured by multi-stage patent citation analysis. Research Policy 34, 1591-1607.

Wasserman, S. \& Faust, K., 1994. Social network analysis: Methods and applications. Cambridge University Press, New York.

Weinmann, G., 1980. Conversation networks as communication networks. University of Haifa, Israel.

Wellman, B., 1979. The community question: The intimate networks of east yorkers. American Journal of Sociology 84, 1201-1231.

Wuchty, S., Jones, B. F., \& Uzzi, B., 2007. The increasing dominance of teams in production of knowledge. Science 316, 1036-1039.

Zheng, W., 2010. A social capital perspective of innovation from individuals to nations: Where is empirical literature directing us? International Journal of Management Reviews $12,151-183$. 


\section{Figures}

\section{Figure 1}

Patent Collaboration Network of the Study

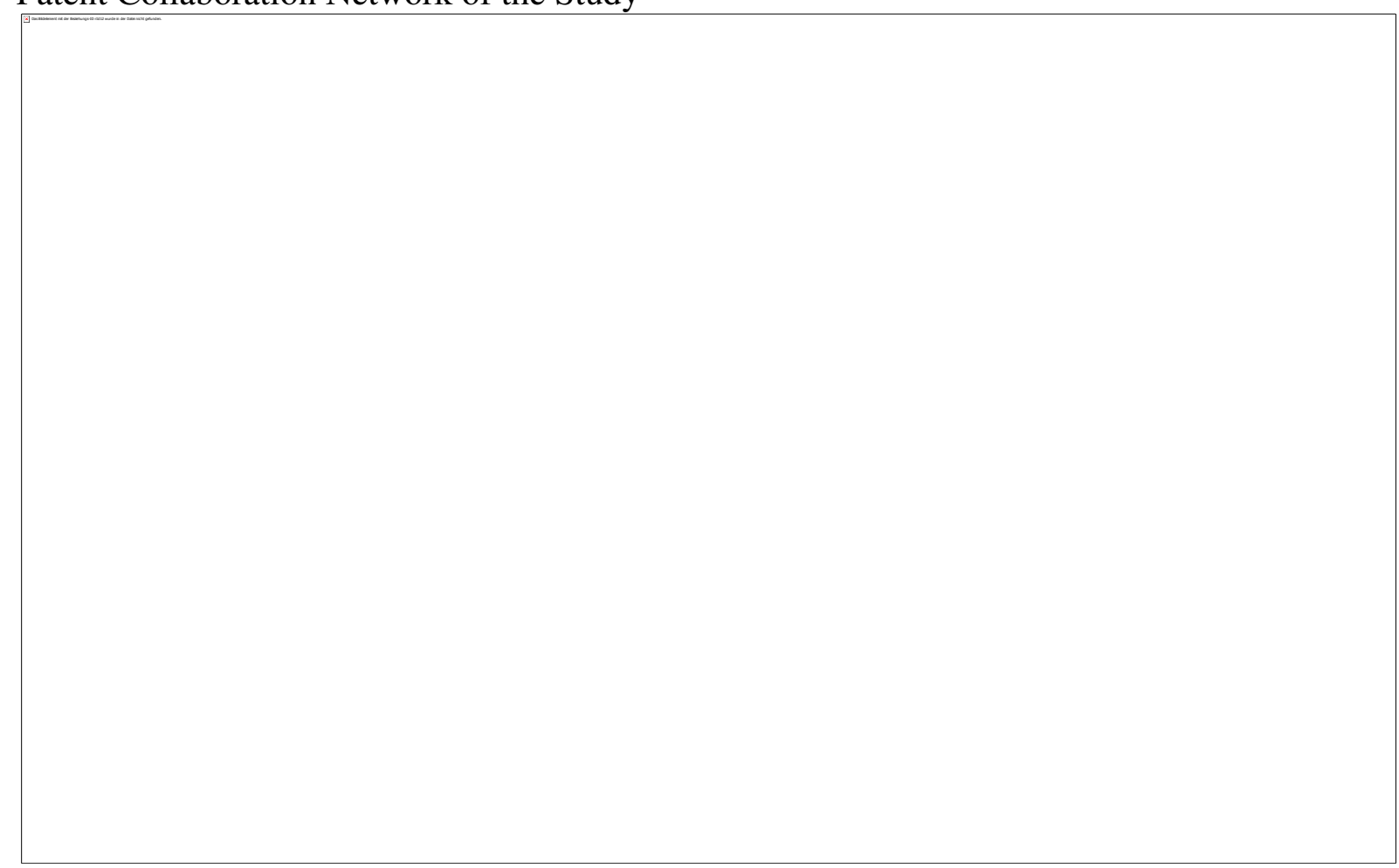

Legend: The figure shows the patent collaborations between 1,788 inventors forming the largest component of the collaboration network identified by the snowball method. Pink circle-in-boxes indicate inventors identified in the first stage of the snowball method, that is, involved in collaboration patents between large German automotive firms. Blue circles indicate inventors identified in the second, third, or fourth stage of the snowball method. Pink and blue inventors, overall 515, constitute the study sample. Grey squares indicate inventors identified in the fifth stage of the snowball method. 


\section{Figure 2}

Pre-test of the name generator in one R\&D firm

Legend: Collaboration networks of 26 R\&D employees (pink circle-in-box) within (blue circle) and outside (grey square) their company. The analysis considers the relationships between Ego's Alteri as indicated by Ego. The network consists of one component. 


\section{Figure 3}

External Validity of Ego Network Closure

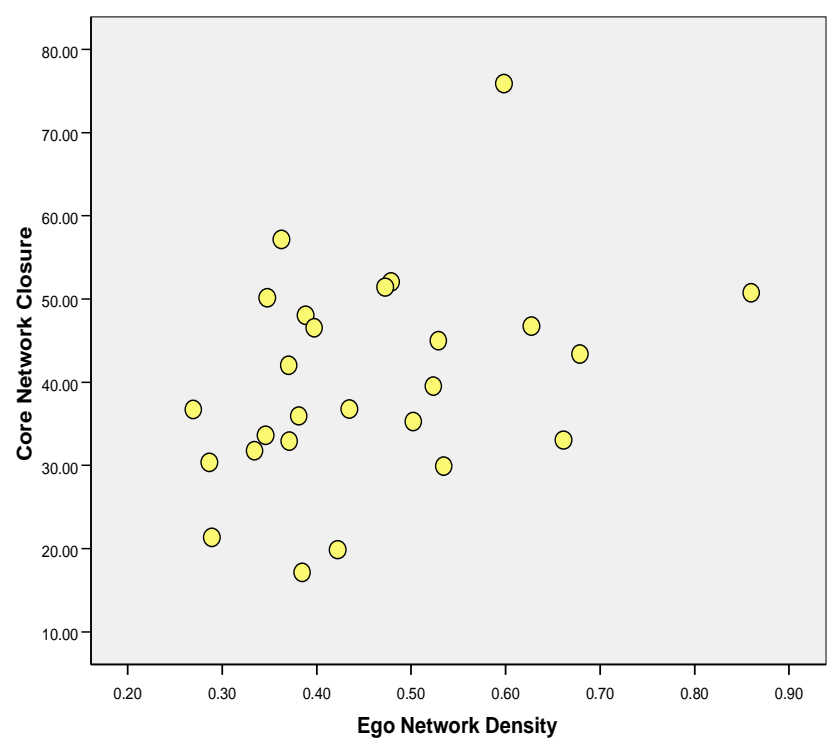

Legend: Relationship between ego network density and a simplified measurement of core network closure calculated from exchange multiplexity and the reciprocal value of ego network size $\left(\mathrm{r}=.440^{*}\right)$. 


\section{Figure 4}

Empirical measurement model: Social capital, human capital, and innovation

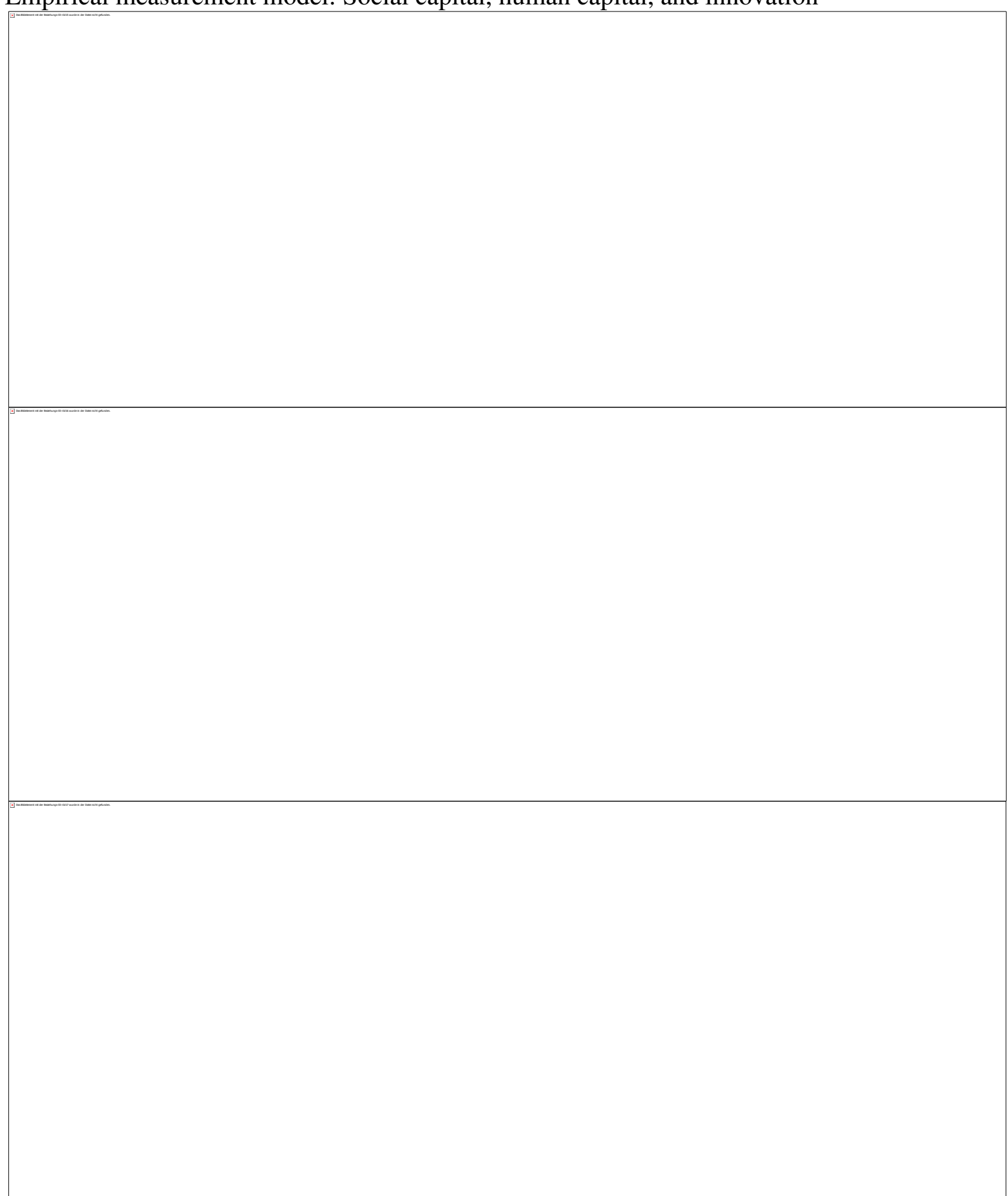

Legend:

Marginal effects (see Tables 3 and 4, column IV).

Weak ties = mean(strength of ties)-SD(strength of ties).

Strong ties $=$ mean $($ strength of ties $)+\mathrm{SD}$ (strength of ties $)$. 


\section{Figure 5}

Theoretical measurement model: social capital and innovation

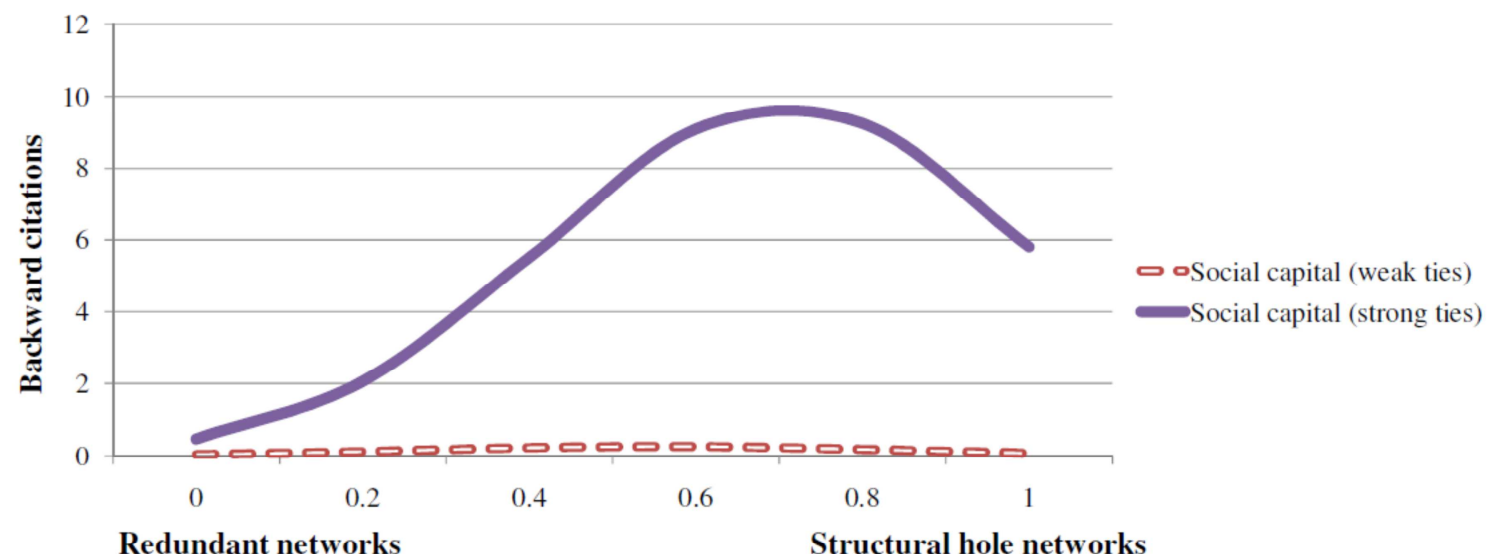

Redundant networks

Structural hole networks
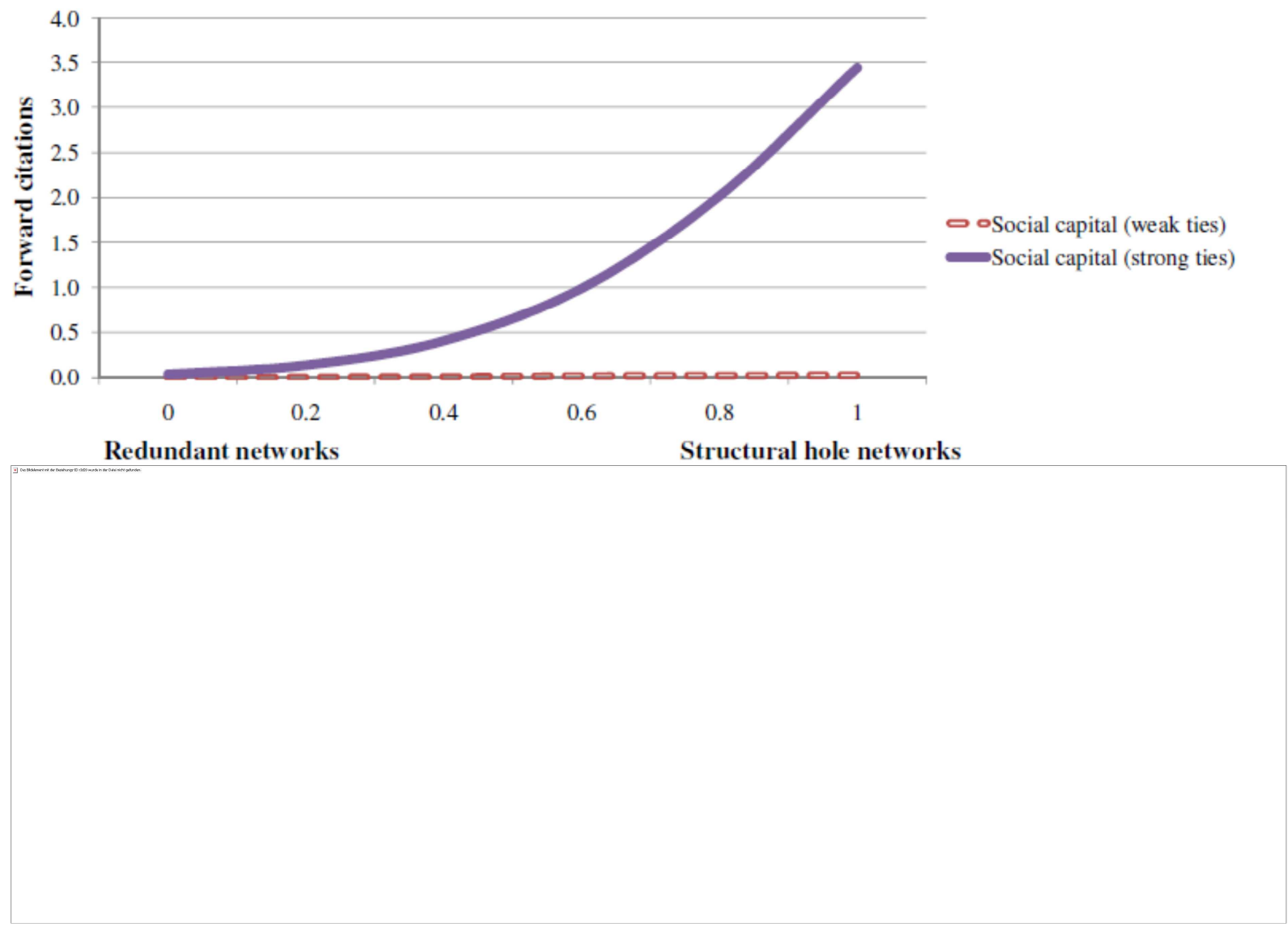

Legend:

Marginal effects (see Table 5).

Weak ties $=$ mean(strength of ties)-SD(strength of ties).

Strong ties $=$ mean(strength of ties) $+\mathrm{SD}$ (strength of ties). 


\section{Tables}

\section{Table 1}

Descriptive statistic of the ego network measurements

Please name those persons from within or from outside your company with which you are currently related in the following relationships.

With which persons you work frequently in projects together?

\begin{tabular}{lll} 
Mean & SD & N \\
\hline 5.52 & 2.13 & 142
\end{tabular}

With which persons you regular exchange information and knowledge about professional issues,

e.g. new developments or new problem solutions?

Assume that you have to solve a tricky and specialized development task, for which only little

$\begin{array}{lll}3.76 & 2.02 & 142\end{array}$

documented knowledge is available. Which persons would you ask for assistance?

Which persons you ask for assistance in the initial stage of a project, e.g. by the search of ideas.

Which persons you ask for assistance in the implementation stage of projects, e.g., transferring

$3.43 \quad 1.60 \quad 142$

results into other operational departments.

Which persons you ask for assistance in the final stage of project, e.g., project management

Please name those persons of your direct work environment, who actively encourage an

$\begin{array}{lll}3.00 & 1.68 & 142\end{array}$

$2.30 \quad 1.24 \quad 142$

$2.45 \quad 1.40 \quad 142$

innovation process by means of specific knowledge. In particular, those persons who are proven technical and/or procedure-specific experts in innovation projects and who assist by the development of new products or procedure.

Please name those persons of your direct work environment, who actively promote an innovation process by means of hierarchic power. In particular, those persons who order sanctions against opponents and provide protection for those who are in favor of innovation.

Please name those persons of your direct work environment, who actively arbitrate between the technical and economic world by means of organizational knowledge. In particular, those persons who recognize organizational hurdles and contribute to innovation processes through their negotiation capabilities.

Please name those persons of your direct work environment, who actively encourage an innovation process by means of innovation-related business relationships inside and outside the organization. In particular, those persons who initiate, design, and foster relationships to important actors and third parties.

Please name those persons of your direct work environment, who actively support crossorganizational knowledge transfer. In particular, those persons who assist and help by searching out and evaluating external technical information.

Which persons you accept as your direct supervisors?

$\begin{array}{lll}1.97 & 1.19 & 142\end{array}$

Which persons have in the past contributed to your career?

$\begin{array}{lll}3.36 & 1.24 & 142\end{array}$

Which persons will in the future contribute to your career?

\begin{tabular}{lll}
$2.26 \quad .90 \quad 142$ \\
\hline
\end{tabular}


Table 2

Dimensions of social capital in the empirical measurement model

\begin{tabular}{|c|c|c|c|c|c|c|c|c|c|}
\hline $\begin{array}{l}\text { Items/ } \\
\text { Factor Loadings }\end{array}$ & Mean & Std. Dev. & Min & Max & $\begin{array}{l}\text { Strength } \\
\text { of ties }\end{array}$ & $\begin{array}{l}\text { Ego Network } \\
\text { Closure }\end{array}$ & $\begin{array}{l}\text { Structural } \\
\text { Holes }\end{array}$ & $\begin{array}{l}\text { Peripheral } \\
\text { Position }\end{array}$ & Overall \\
\hline Alteri's perceived creativity/innovativeness & 2.91 & 0.71 & 1.80 & 5.00 & .90 & & & & \\
\hline Alteri's level of education & 3.04 & 0.75 & 1.83 & 5.00 & .88 & & & & \\
\hline Alteri's trustworthiness & 2.70 & 0.89 & 1.33 & 5.00 & .83 & & & & \\
\hline Alteri's amount of sector-specific knowledge & 3.24 & 0.69 & 1.89 & 5.00 & .82 & & & & \\
\hline Alteri's specialist-knowledge-proximity & 3.09 & 0.76 & 1.62 & 5.00 & .78 & & & & \\
\hline Alteri's sure-handedness/ reliability & 3.16 & 0.76 & 1.00 & 5.00 & .76 & & & & \\
\hline Alteri's hierarchical position & 1.26 & 0.40 & 0.42 & 2.00 & .76 & & & & \\
\hline Ego-Alteri contact frequency & 2.29 & 0.97 & 0.92 & 5.00 & .71 & & & & \\
\hline Ego's social network size & 12.66 & 6.46 & 3.00 & 41.00 & & -.95 & & & \\
\hline Ego's social exchange multiplexity & 3.55 & 1.36 & 1.24 & 7.50 & & .74 & & & \\
\hline Ego's constraint in patent collaboration networks & 0.55 & 0.26 & 0.15 & 1.13 & & & -.93 & & \\
\hline Ego's patent collaboration's network size & 19.73 & 28.98 & 1.00 & 181.00 & & & .91 & & \\
\hline Percentage of external Alteri in Ego's social network & 0.17 & 0.18 & 0.00 & 1.00 & & & & .83 & \\
\hline Ego's closeness centrality in patent collaboration networks & 10.96 & 2.56 & 0.19 & 14.53 & & & & .62 & \\
\hline Explained Variance & & & & & 38.36 & 16.70 & 11.95 & 7.74 & 74.74 \\
\hline Cronbachs Alpha & & & & & .92 & - & - & - & \\
\hline $\mathrm{N}$ & & & & & & & & & 142 \\
\hline
\end{tabular}




\section{Table 3}

Empirical measurement model: Social capital and integration of prior technological knowledge

\begin{tabular}{|c|c|c|c|c|}
\hline $\begin{array}{l}\text { Dependent variable: } \\
\text { Backward patent citations }_{\mathrm{t} 5}\end{array}$ & $\mathrm{I}$ & II & III & IV \\
\hline Strength of Ties ${ }_{t 0}$ & & $\begin{array}{r}.415 \\
(.958)\end{array}$ & $\begin{array}{r}11.354 \\
(6.688)\end{array}$ & $\begin{array}{rl}31.793 & * \\
(14.726)\end{array}$ \\
\hline Strength of Ties Square ${ }_{t 0}$ & & & $\begin{array}{r}-7.73 \\
(5.137)\end{array}$ & $\begin{array}{l}-15.573 * * \\
(5.765)\end{array}$ \\
\hline Ego Network Closure $_{\mathrm{t} 0}$ & & $\begin{array}{r}-1.384 \\
(.734)\end{array}$ & $\begin{array}{r}-.867 \\
(4.247)\end{array}$ & $\begin{array}{r}6.157 \\
(9.598)\end{array}$ \\
\hline Ego Network Closure Square $_{\mathrm{t} 0}$ & & & $\begin{array}{r}-.293 \\
(3.733)\end{array}$ & $\begin{array}{r}-2.319 \\
(3.632)\end{array}$ \\
\hline Structural Holes $_{\text {t0 }}$ & & $\begin{array}{r}.297 \\
(.719)\end{array}$ & $\begin{array}{l}5.848 * * \\
(2.107)\end{array}$ & $\begin{array}{r}2.052 \\
(2.692)\end{array}$ \\
\hline Structural Holes Square $_{\mathrm{t} 0}$ & & & $\begin{array}{l}-6.463 * * \\
(2.212)\end{array}$ & $\begin{array}{l}-9.484 * * * \\
(2.35)\end{array}$ \\
\hline Peripheral Position $_{\mathrm{t} 0}$ & & $\begin{array}{r}-.197 \\
(1.1)\end{array}$ & $\begin{array}{l}6.204 * * \\
(2.378)\end{array}$ & $\begin{array}{r}19.206 \\
(12.546)\end{array}$ \\
\hline Peripheral Position Square $_{t 0}$ & & & $\begin{array}{l}-7.426 * * \\
(2.698)\end{array}$ & $\begin{array}{l}-10.337 * * * \\
(2.786)\end{array}$ \\
\hline Strength of Ties $_{\mathrm{t} 0} \mathrm{x}$ Ego Network Closure ${ }_{\mathrm{t} 0}$ & & & & $\begin{array}{r}-10.413 \\
(17.762)\end{array}$ \\
\hline Strength of Ties ${ }_{t 0} \times$ Structural Holes ${ }_{t 0}$ & & & & $\begin{array}{l}12.128 * * \\
(4.287)\end{array}$ \\
\hline Strength of Ties ${ }_{\mathrm{t} 0} \mathrm{x}$ Peripheral Position ${ }_{\mathrm{t} 0}$ & & & & $\begin{array}{r}-23.244 \\
(25.584)\end{array}$ \\
\hline Fast vs. slow technological change $e_{t 0}$ & $\begin{array}{l}-.024 \\
(.056)\end{array}$ & $\begin{array}{r}-.07 \\
(.068)\end{array}$ & $\begin{array}{l}-.174 * \\
(.072)\end{array}$ & $\begin{array}{l}-.210 * * \\
(.072)\end{array}$ \\
\hline Few vs. many documented knowledge ${ }_{t 0}$ & $\begin{array}{l}-.189 * * \\
(.07)\end{array}$ & $\begin{aligned}-.141 \\
(.077)\end{aligned}$ & $\begin{array}{l}-.187 * \\
(.086)\end{array}$ & $\begin{array}{l}-.235 * * \\
(.087)\end{array}$ \\
\hline Job engagement $t_{t 0}$ & $\begin{array}{r}.248 \\
(.21)\end{array}$ & $\begin{array}{r}.317 \\
(.218)\end{array}$ & $\begin{array}{c}.416 * \\
(.207)\end{array}$ & $\begin{array}{r}.323 \\
(.218)\end{array}$ \\
\hline Hierarchical position $_{\mathrm{t} 0}$ & $\begin{array}{r}.149 \\
(.105)\end{array}$ & $\begin{array}{r}.143 \\
(.103)\end{array}$ & $\begin{array}{c}.232 \\
(.107)\end{array}$ & $\begin{array}{l}.283 \\
(.105)\end{array}$ \\
\hline Highest education $_{\mathrm{t} 0}$ & $\begin{array}{r}.084 \\
(.116)\end{array}$ & $\begin{array}{r}.034 \\
(.123)\end{array}$ & $\begin{array}{r}.128 \\
(.13)\end{array}$ & $\begin{array}{r}.141 \\
(.133)\end{array}$ \\
\hline Work experience in years $t_{0}$ & $\begin{array}{l}.006 \\
(.01)\end{array}$ & $\begin{array}{r}.007 \\
(.011)\end{array}$ & $\begin{array}{r}.012 \\
(.011)\end{array}$ & $\begin{array}{l}.027 * \\
(.012)\end{array}$ \\
\hline Average inventors per patent $t_{t 0}$ & $\begin{array}{l}.424 * * * \\
(.066)\end{array}$ & $\begin{array}{l}.434 * * * \\
(.077)\end{array}$ & ${ }_{(.072)}^{.42} * * *$ & $\begin{array}{l}.443 \\
(.072)\end{array}$ \\
\hline Average priority year per patent $t_{0}$ & $\begin{array}{l}-.297 * \\
(.12)\end{array}$ & $\begin{array}{l}-.295 * \\
(.122)\end{array}$ & $\begin{array}{r}-.179 \\
(.121)\end{array}$ & $\begin{array}{r}-.104 \\
(.119)\end{array}$ \\
\hline Number of patents ${ }_{t 0}$ & ${ }_{(.015)}^{.143^{* * *}}$ & 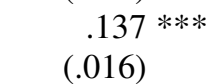 & $\begin{array}{l}.153 * * * \\
(.016)\end{array}$ & $\begin{array}{l}.159 \\
(.015)\end{array}$ \\
\hline _cons & $\begin{array}{l}595.324 * \\
(239.578)\end{array}$ & $\begin{array}{l}591.146 * \\
(244.432)\end{array}$ & $\begin{array}{l}351.316 \\
(243.38)\end{array}$ & $\begin{array}{r}193.4 \\
(240.001)\end{array}$ \\
\hline Pseudo R2 & .1151 & .1183 & .1352 & .1461 \\
\hline LR chi2 & $141.08 * * *$ & $144.95 * * *$ & $165.72 * * *$ & $179.04 * * *$ \\
\hline Log likelihood & -542.17 & -540.24 & -529.85 & -523.20 \\
\hline Likelihood-ratio test (df) & - & 3.86 & $20.77 * * *$ & $13.33 * *$ \\
\hline $\mathrm{N}$ & 142 & 142 & 142 & 142 \\
\hline
\end{tabular}

\section{Legend:}

Negative binomial regression

$* * * \mathrm{p}<.001, * * \mathrm{p}<.01, * \mathrm{p}<.05$ 


\section{Table 4}

Empirical measurement model: Social capital and creation of new technological knowledge

Dependent variable:
Forward patent citations ${ }_{\mathrm{t}} 5$
Strength of Ties $_{\mathrm{t} 0}$

Strength of Ties Square ${ }_{\mathrm{t} 0}$

Ego Network Closure ${ }_{\mathrm{t} 0}$

Ego Network Closure Square ${ }_{\mathrm{t} 0}$

Structural Holes $_{\text {t0 }}$

Structural Holes Square $_{\text {to }}$

Peripheral Position $_{\mathrm{t} 0}$

III

IV

V

Peripheral Position Square ${ }_{t 0}$

Strength of Ties ${ }_{t 0} \mathrm{x}$ Ego Network Closure ${ }_{\mathrm{t} 0}$

Strength of Ties ${ }_{t 0} \times$ Structural Holes $_{\mathrm{t} 0}$

Strength of Ties $\mathrm{t}_{0} \mathrm{x}$ Peripheral Position ${ }_{\mathrm{t} 0}$

Fast vs. slow technological change ${ }_{t 0}$

Few vs. many documented knowledge ${ }_{t 0}$

$(.074)$

$-.146$

(.094)

Job engagement ${ }_{\mathrm{t} 0}$

Hierarchical position $_{\mathrm{t} 0}$

$-.142$

(.139)

Highest education $_{\mathrm{t} 0}$

Work experience in years ${ }_{t 0}$

$(.159)$

$-.002$

$(.015)$

Average inventors per patent ${ }_{t 0}$

Average priority year per patent to

Number of patents ${ }_{t 0}$

_cons

$.321 * * *$

$(.084)$

$-.421 *$

$(.172)$

$.156 * * *$

.005

(.086)

$-.104$

(.107)

.336

(.288)

$-.116$

(.141)

.192

(.175)

$-.008$

(.016)

$1.519)$

$$
\text { (.021) }
$$

$842.21 *$ (345.348)

Pseudo R2

LR chi2

Log likelihood

Likelihood-ratio test (df)

$\mathrm{N}$

Legend:

Negative binomial regression

$* * * \mathrm{p}<.001, * * \mathrm{p}<.01,{ }^{*} \mathrm{p}<.05$

$\begin{array}{rr}4.083 & 60.653 \\ (9.059) & (20.055) \\ -2.336 & -17.638 \\ (6.832) & (7.527)\end{array}$

(6.832) (7.527)

$16.166 * \quad 21.607$

(7.174) (13.188)

$-12.594 * \quad-13.468 *$

(6.075) (5.828)

$1.64 \quad-2.585$

(3.07) (3.891)

$-1.986 \quad-4.226$

(3.11) (3.258)

$11.736 * * * \quad 50.861 * *$

(3.147) (15.647)

$-13.239 * * * \quad-17.958 * * *$

(3.638) (3.792)

$-10.964$

(22.496)

$10.825 *$

(5.378)

$-76.883 *$

(31.925)

$$
\begin{array}{ll}
-.063 \quad-.106 \\
(.093)
\end{array}
$$

(.093) (.092)

$-.164 \quad-.216$

(.112) (.119)

.366 308

(.291) (.294)

$-.107 \quad-.108$

(.16) (.155)

$.298 \quad .431 *$

(.170) (.176)

$.009 \quad .030$

(.017) (.018)

$.358 * * * \quad .287 * * \quad .340 * * *$

$\begin{array}{lll}(.096) & (.089) \quad(.092)\end{array}$

$\begin{array}{lll}. .472 * * & -.24 & -.124\end{array}$

$\begin{array}{lll}(.172) & (.17) \quad(.171)\end{array}$

$.156 * * * \quad .172 * * * \quad .180 * * *$

$\begin{array}{lll}(.022) & (.021) \quad(.020)\end{array}$

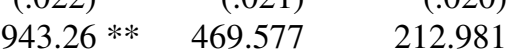

$\begin{array}{lll}(345.156) & (341.462) \quad(344.228)\end{array}$

\begin{tabular}{rccc}
.1511 & .1574 & .1794 & .2012 \\
$105.09 * * *$ & $109.48 * * *$ & $124.76 * * *$ & $139.97 * * *$ \\
-295.25 & -293.06 & -285.42 & -277.81 \\
- & 4.39 & $15.28 * *$ & $15.22 * *$ \\
142 & 142 & 142 & 142 \\
\hline
\end{tabular}




\section{Table 5}

Theoretical measurement model: Social capital and technological knowledge

\begin{tabular}{|c|c|c|}
\hline \multirow{2}{*}{$\begin{array}{l}\text { Dependent variable: } \\
\text { Strength of Ties to }\end{array}$} & Backward patent citations $\mathrm{t}_{\mathrm{t}}$ & Forward patent citations ${ }_{t 5}$ \\
\hline & $\begin{array}{c}28.514 \dagger \\
(15.027)\end{array}$ & $\begin{array}{r}25.405 \\
(26.833)\end{array}$ \\
\hline Strength of Ties Square ${ }_{t 0}$ & $\begin{array}{l}-8.142 \dagger \\
(4.42)\end{array}$ & $\begin{array}{r}-2.260 \\
(5.375)\end{array}$ \\
\hline 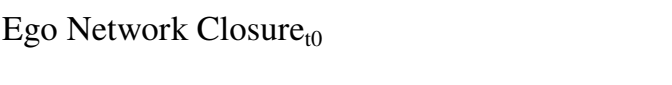 & $\begin{array}{r}-1.690 \\
(5.589)\end{array}$ & $\begin{array}{l}-19.934 * * \\
(7.541)\end{array}$ \\
\hline Ego Network Closure Square ${ }_{\text {t0 }}$ & $\begin{array}{r}2.030 \\
(3.744)\end{array}$ & $\begin{array}{l}13.607 * * \\
(4.887)\end{array}$ \\
\hline Structural Holes to & $\begin{array}{r}.327 \\
(3.746)\end{array}$ & $\begin{array}{r}-2.871 \\
(4.272)\end{array}$ \\
\hline Structural Holes Square $_{\text {t0 }}$ & $\begin{array}{l}-6.029 * \\
(3.01)\end{array}$ & $\begin{array}{r}-2.246 \\
(4.279)\end{array}$ \\
\hline Peripheral Position ${ }_{t 0}$ & $\begin{array}{l}15.972 * \\
(7.396)\end{array}$ & $\begin{array}{l}28.253 * \\
(14.314)\end{array}$ \\
\hline Peripheral Position Square ${ }_{t 0}$ & $\begin{array}{r}-.651 \\
(3.812)\end{array}$ & $\begin{array}{l}-8.859 \dagger \\
(4.892)\end{array}$ \\
\hline Strength of Ties to $_{0} \mathrm{x}$ Ego Network Closure ${ }_{t 0}$ & $\begin{array}{r}-5.747 \\
(4.206)\end{array}$ & $\begin{array}{r}-4.898 \\
(5.288)\end{array}$ \\
\hline Strength of Ties ${ }_{t 0} \times$ Structural Holes ${ }_{t 0}$ & $\begin{array}{l}16.161 * \\
(7.199)\end{array}$ & $\begin{array}{l}18.887 * \\
(9.136)\end{array}$ \\
\hline Strength of Ties ${ }_{t 0} \times$ Peripheral Position ${ }_{t 0}$ & $\begin{array}{l}-26.799 \dagger \\
(14.095)\end{array}$ & $\begin{array}{r}-35.321 \\
(27.269)\end{array}$ \\
\hline Fast vs. slow technological change ${ }_{t 0}$ & $\begin{array}{l}-.211 * * \\
(0.069)\end{array}$ & $\begin{array}{l}-.202 \\
(0.096)\end{array}$ \\
\hline Few vs. many documented knowledge ${ }_{t 0}$ & $\begin{array}{r}-.123 \\
(0.079)\end{array}$ & $\begin{array}{r}-.036 \\
(0.121)\end{array}$ \\
\hline Job engagement to & $\begin{array}{r}.311 \\
(0.201)\end{array}$ & $\begin{array}{r}.430 \\
(0.301)\end{array}$ \\
\hline Hierarchical position $_{\mathrm{t} 0}$ & $\begin{array}{c}.205 \dagger \\
(0.117)\end{array}$ & $\begin{array}{r}.075 \\
(0.167)\end{array}$ \\
\hline Highest education $_{\mathrm{t} 0}$ & $\begin{array}{r}-.008 \\
(0.111)\end{array}$ & $\begin{array}{r}.014 \\
(0.147)\end{array}$ \\
\hline Work experience in years $t 0$ & $\begin{array}{c}.020 \dagger \\
(0.012)\end{array}$ & $\begin{array}{r}.022 \\
(0.015)\end{array}$ \\
\hline Average inventors per patent ${ }_{t 0}$ & $\begin{array}{l}.485 * * * \\
(0.07)\end{array}$ & $\begin{array}{l}.333 * * * \\
(0.087)\end{array}$ \\
\hline Average priority year per patent $t 0$ & $\begin{array}{r}-.140 \\
(0.112)\end{array}$ & $\begin{array}{r}-.139 \\
(0.16)\end{array}$ \\
\hline Number of patents ${ }_{t 0}$ & $\begin{array}{l}.137 * * * \\
(0.016)\end{array}$ & $\begin{array}{l}.135 * * * \\
(0.019)\end{array}$ \\
\hline Patent Collaboration Network Size ${ }_{t 0}$ & $(0.014)$ & $\begin{array}{r}.004 \\
(0.021)\end{array}$ \\
\hline Ego Network Size ${ }_{\text {t0 }}$ & $\begin{array}{l}-5.509 \dagger \\
(2.927)\end{array}$ & $\begin{array}{l}-9.364 * \\
(3.707)\end{array}$ \\
\hline Amount of external contacts in Ego networks to & $\begin{array}{l}-1.590 * \\
(0.686)\end{array}$ & $\begin{array}{r}-1.018 \\
(0.814)\end{array}$ \\
\hline _cons & $\begin{array}{r}266.758 \\
(224.511) \\
\end{array}$ & $\begin{array}{r}270.593 \\
(321.695) \\
\end{array}$ \\
\hline Pseudo R2 & .1676 & .2129 \\
\hline LR chi2 & $205.40 * * *$ & $148.07 * * *$ \\
\hline Log likelihood & -510.01 & -273.76 \\
\hline Likelihood-ratio test (df) & $17.89 * * *$ & $13.88 * *$ \\
\hline $\mathrm{N}$ & 142 & 142 \\
\hline
\end{tabular}

Legend:

Negative binomial regression

$* * * \mathrm{p}<.001, * * \mathrm{p}<.01,{ }^{*} \mathrm{p}<.05, \dagger \mathrm{p}<.10$ 


\section{Appendix}

Table A-1

Descriptive statistics and correlations

\begin{tabular}{|c|c|c|c|c|c|c|c|c|c|c|c|c|c|c|c|c|c|c|c|}
\hline & & Mean & Std. Dev. & Min & Max & 1 & 2 & 3 & 4 & 5 & 6 & 7 & 8 & 9 & 10 & 11 & 12 & 13 & 14 \\
\hline 1 & Forward patent citations $_{\mathrm{t} 5}$ & 5.86 & 10.72 & .00 & 44 & & & & & & & & & & & & & & \\
\hline 2 & Backward patent citations $_{\mathrm{t} 5}$ & 43.86 & 64.50 & .00 & 279 & .758 & & & & & & & & & & & & & \\
\hline 3 & Strength of Ties ${ }_{t 0}$ & .46 & .05 & .35 & .66 & .051 & .000 & & & & & & & & & & & & \\
\hline 4 & Ego Network Closure $_{t 0}$ & .58 & .15 & .16 & 1 & -.055 & -.105 & -.018 & & & & & & & & & & & \\
\hline 5 & Structural Holes $_{\mathrm{t} 0}$ & .37 & .19 & .03 & 1 & .162 & .177 & .092 & .016 & & & & & & & & & & \\
\hline 6 & Peripheral Position $_{\mathrm{t} 0}$ & .50 & .14 & .00 & 1 & -.032 & -.039 & -.140 & -.022 & .041 & & & & & & & & & \\
\hline 7 & Fast vs. slow technological change ${ }_{t 0}$ & .04 & 1.93 & -3 & 3 & .027 & .020 & .161 & -.108 & -.203 & -.158 & & & & & & & & \\
\hline 8 & Few vs. many documented knowledge ${ }_{t 0}$ & .26 & 1.55 & -3 & 3 & -.069 & -.181 & -.088 & .108 & -.295 & -.133 & .300 & & & & & & & \\
\hline 9 & Job engagement $t_{t 0}$ & 2.64 & .88 & 0 & 4 & -.034 & -.001 & .015 & .174 & -.204 & .213 & .051 & .099 & & & & & & \\
\hline & Hierarchical position $_{\mathrm{t} 0}$ & 2.27 & .96 & 1 & 5 & -.006 & .088 & -.002 & .027 & -.122 & .265 & .114 & -.003 & .338 & & & & & \\
\hline & Highest education $_{\mathrm{t} 0}$ & 2.27 & .93 & 1 & 5 & .005 & -.041 & -.175 & -.183 & -.055 & .170 & .095 & .268 & .076 & .239 & & & & \\
\hline 12 & Work experience in years ${ }_{t 0}$ & 23.90 & 10.58 & 7 & 46 & -.128 & -.092 & .018 & .272 & .053 & .260 & .030 & -.027 & .389 & .292 & -.025 & & & \\
\hline 13 & Average inventors per patent $t_{0}$ & 2.68 & 2.40 & 0 & 8.33 & .403 & .455 & -.172 & -.147 & .375 & .020 & -.134 & -.257 & -.129 & -.090 & -.054 & -.146 & & \\
\hline & Average priority year per patent $t 0$ & 2006.31 & .85 & 2004 & 2009 & .028 & .049 & .029 & .099 & -.092 & .165 & .043 & .126 & .305 & .031 & -.030 & .064 & -.025 & \\
\hline 15 & Number of patents $t 0$ & 6.43 & 8.91 & 0 & 43 & .627 & .906 & .008 & -.079 & .193 & -.094 & -.115 & -.210 & .026 & .065 & -.034 & -.128 & .385 & .136 \\
\hline
\end{tabular}

Legend:

$\mathrm{N}$ obs 142 
